\title{
REFINING THE MATERIAL SUBSTANCE: ARISTOTLE'S PROGRAM IN METAPHYSICS H1-5
}

\author{
Fabián Mié ${ }^{1}$ \\ CONICET - IHuCSo Litoral, Universidad Nacional del Litoral (Argentina)
}

Recibido: 25.09.2018 - Aceptado: 26.10.2018

\begin{abstract}
RESUMEN
En Metaph. Z17, Aristóteles toma un nuevo punto de partida (1041a6) en su discusión sobre la sustancia: la forma sustancial es principio y causa (1041a6-10, 1041b8), mientras que la materia es un elemento (1041b31) de las sustancias materiales. Además, un compromiso de Aristóteles, quizá no totalmente aclarado en $Z 17$, es que las sustancias materiales son todos unificados (1041b11-12). Éstas son dos tesis centrales de Z17, cuya aparente ausencia en el resumen de H1 (1042a3-23) ha despertado dudas entre los comentadores acerca del mismo proyecto de $\mathrm{H}$; un libro que es visto comúnmente como un mero manojo de notas sobre temas de Z. En cuanto a la contribución positiva de $\mathrm{H}$, los comentadores destacan poco más que la introducción del vocabulario modal de potencia y acto, en el cual se habría traducido la distinción de $Z$ entre materia y forma; y encuentran recién en la solución que H6 (1045a23-25, 1045b18-19) ofrece al problema de la unidad la genuina contribución que hace el entero libro H. Como consecuencia de esta lectura, H1-5 quedan a la sombra de H6 y resultan escasamente atendidos. En contra de la tendencia todavía predominante a no considerar H1-5 en sí mismos, en este artículo intentaré mostrar que esos capítulos desarrollan un programa que prepara adecuadamente la conclusión de H6. H2-3 son la primera gran estación en ese programa; allí Aristóteles justifica la prioridad de la forma; posteriormente, en H4-5 hace algo similar con la unidad de los compuestos materiales. De tal manera, trataré de mostrar que H1-5 constituyen una pieza central en el acabamiento de la teoría sobre la sustancia material iniciada en Z17.
\end{abstract}

Palabras clave: forma; causa; unidad; potencia; acto.

\begin{abstract}
In Metaph. Z17, Aristotle makes a fresh start (1041a6) in his discussion on substance. Accordingly, the substantial form is principle and cause (1041a6-10, 1041b8), whereas the matter is element (1041b31) of material substances. Besides, Aristotle assumes (probably without justifying in Z17) that material substances are unified wholes (1041b11-12). These are two main theses in Z17 whose apparent absence in the summary of H1 (1042a3-23) has raised doubts among commentators as to the very project of $\mathrm{H}-\mathrm{a}$ book commonly held to be a bunch of notes on Z. Regarding H's positive results, commentators mostly focus on the introduction of the modal vocabulary of potentiality and actuality -into which Z's distinction between matter and form is translated. So they find book's $H$ proper contribution only in H6's solution to the problem of unity (1045a23-25, 1045b18-19). As a consequence of this reading, $\mathrm{H} 1-5$ remain overshadowed by H6, and therefore they are often neglected. Contrarily to this still predominant trend towards not taking H15 on their own, I will here try to show that these chapters develop a program, in which H6's conclusion is properly prepared. Stations of this program are $\mathrm{H} 2-3$, where Aristotle justifies the priority of form, and then H4-5, where he does the same for the unity of material compounds. So, I aim to show that H1-5 are a centerpiece in the completion and fulfilment of Z17's theory of material substance.
\end{abstract}

Keywords: form; cause; unity; potentiality; actuality.

\footnotetext{
1 fabian.mie@conicet.gov.ar
} 


\section{THE "EVOLUTION" OF MATERIAL SUBSTANCE IN METAPHYSICS $\mathrm{ZH}$}

Let us imagine for a moment that it is possible to consider the Aristotelian substance similarly to the way evolutionists consider natural kinds. We could, then, ask questions about the "evolution" of material substance. This attitude would enable us to interpret Metaphysics ZH -where the "evolution" I want to consider takes place- in terms of the "development" of the philosophical argument launched in Z17 and continued in the following book H. So we could try to single out the program that takes shape along these books. On the contrary, if we believe we could read $\mathrm{ZH}$ and get by without the hypothesis of a program -which is, for the moment, a merely heuristic assumption-, then ZH's claims could be seen as theoretically isolated developments deprived of any inner connection, or even as fragments or pieces of an argument with no clear objective. On the contrary, the approach I propose here to undertake will enable us to ask the following questions: how did Aristotelian substance "evolve" between Z17 and H6?; which were the specific features of substance in both stages of this "evolution"?; how do we have to describe the "development" of this "evolution"?; which exactly is its starting point, which is its arrival point, and which are its halfway points?; was perhaps this sort of "evolution" a linear process or were there several detours and truncated "developments" along these chapters that could have given rise to other "species"? It is quite obvious that these are not questions about the purported author's "evolution." By raising these questions, we do not make any assumption from the start as to whether Aristotle firmly upheld one coherent thesis from Z17 to H6, or he rather changed his mind along these chapters. Whether or not the author had a preconceived plan when writing on substance between $\mathrm{Z}$ and $\mathrm{H}$ is not a question I am interested in raising here. For that reason, I will leave aside any speculation about possible double versions of some chapters of $Z$ as well as any discussion about the relative dating of $Z$ and $H$. So I will put aside considerations as to whether Aristotle tried to reformulate $\mathrm{Z}$ after having achieved some new views on material substance in $\mathrm{H}^{2}$ On the contrary -and this is certainly not an uncontroversial hypothesis on these books-, I will here take $\mathrm{ZH}$ as they stand, i.e. I will consider them as if they were "evolutionary" terminals of a successful argumentative process. I am interested in finding out both the main features of this "species" -called material substance - that became steady between Z17 and H6 and the

\footnotetext{
${ }^{2}$ For a similar approach on Metaph. ZH see Devereux 2003.
} 
"evolutionary" way that enabled material substance to finally reach that position.

The famous paleontologist Stephen Jay Gould once claimed that while nature's message lies in its generality, nature's beauty lies in the details. ${ }^{3}$ This inspiring claim could help us to examine (mutatis mutandis) Z17-H6's argument. It seems possible to assume the heuristic hypothesis that these chapters contain the "evolution" of material substance, and that they draw some linear argument, which, however, is not to be seen as lacking any halfway complexities. But, despite the latter, such a linear argument may have launched some program about the material substance. One outstanding feature of this linear development -I would like to suggest- is that, if we focus exclusively on H6's general message without paying attention to the argumentative details deployed in the intermediate chapters, we cannot really understand the entire argument of Z17-H6. Under this hypothesis, H6's consecrated seat of honor as to the metaphysical message of these books will remain undisputed since we will still recognize H6's achievements as to the solution of the unity of material substance by means of the modal notions of potentiality and actuality -this is the homo sapiens of our history. However, my claim is that, in order to fully understand this message, it is necessary to dig into the details of H1-5 to find out the very argumentative support that could ground the meaning of that message and that give H6's solution its proper conceptual soundness and acceptability.

But this (loose) comparison between Paleontology and Zetology (or rather Etology) should be clearer now. Here I am neither suggesting that Z17 presents a "species" different from that found in H6 nor that H1-5 could be seen as being developmentally independent from H6's terminal. What I am proposing is rather that Z17's main innovation -i.e. the thesis that substantial form is causeis on the same "phylogenic line" of H6, and further that Z17 relates to H6's main claim -i.e. that form and matter constitute a strong unity since form actualizes the compound's proximate matter- similarly to what paleontologists claim about the homo erectus as to the development of intellectual capacities in the sapiens. In my picture, form as cause -the homo erectus of Z17- results in the unity of composite substances that are wholes rather than mere heaps or sums of parts in H6. This feature, which is already developed in Z17, is crucially refined along H's chapters until establishing a successful explanation of the compound's unity in H6 -this is where we find the homo sapiens in this

${ }^{3}$ Gould 1989 makes this claim about the importance that some invertebrates founded in Burgess Shale would have for the history of evolution. Among Gould's predecessors in celebrating the details of nature see Aristotle, PA I 5, 645a15-17: "Therefore we must avoid a childish distaste for examining the less valued animals. For in all natural things there is something wonderful" (Balme's translation). 
"evolutionary" history. In H6, Aristotle solves indeed the problem of unity between the potential matter and the actual form of a compound (1045a23-25, b18$22)$. But this explanation can be only reached over the course of the arguments deployed in H1-5. This is the Aristotelian history of material substance between Z17 and H6 that I would like to tell here. ${ }^{4}$

Before briefly considering the two terminals of this history in Z17 and H6, and before examining in detail the transition between $\mathrm{H} 1$ and $\mathrm{H} 5$, it might be convenient to make a short remark on the current state of the art about book $\mathrm{H}$. There are still great discrepancies among scholars as to the role and importance of H1-5 within ZH's argument. Until recent years, H1-5 remained overshadowed by the big foliage of the justly celebrated chapters (i.e. Z17 and H6) that frame H1-5. My aim here is to describe the "evolutionary" intermediate stages in which material substance is between Z17 and H6, and, further, to make it make plausible that $\mathrm{H} 6$ is the completion and fulfillment of Z17's argument, which is only reached by means of H1-5. Therefore, I think that the following caveat should be repeated: it could happen that without paying sufficient attention to the "evolution" of the argument that ends up in H6 we may lose sight of the very difficulties to which H6's responses are solutions. So I suggest that only by a careful reading of H1-5 we will be in a position to better understand how H6's brief response to the problem of unity is elaborated. H6's solution is intentionally presented by Aristotle in a quite easy way; he simply claims that, once we have avoided some false assumptions about form and matter -mainly that they are two independent items-, the problem about the compound's unity no longer exists:

However, if, as we say, on the one hand there is matter and on the other hand there is form, and one is potentially while the other is actually, what we inquire will no longer seem to be a difficulty. (H6, $1045 \mathrm{a} 23-25)^{5}$

Yet, this triumphant solution cannot be fully understood without the background of H1-5.

\footnotetext{
${ }^{4}$ Morel 2015 suggests that $\mathrm{H}$ refines (without replacing) the hylomorphism of $\mathrm{Z}$ by means of the modal concepts of potentiality and actuality. This involves, according to him, a rehabilitation of the material subject as substance -which, in turn, is only possible when the material subject becomes a determinate part of the compound. This last question involves an interpretation of Z3's indeterminate substrate -which could not be substance, according to Aristotle (1029a27) - and its possible relation to the modal conception of matter in H4-5. I briefly discuss this topic here below.

${ }^{5}$ I quote Jaeger's text in OCT (1957). These versions are my own translations based on Ross 1924 and Bostock 1994. Angle brackets mark additions in the translation.
} 
At this point, it should be quite plain that my approach to $\mathrm{H}$ does not share the once popular anti-linear view defended by commentators such as Ross, ${ }^{6}$ Bostock, ${ }^{7}$ and -to some extent- the Londinensis, ${ }^{8}$ for whom, generally speaking, book $\mathrm{H}$ is a miscellany of notes about several topics raised in Z. I rather tend to share the view of more recent authors such as Burnyeat, ${ }^{9} \mathrm{Gill},{ }^{10}$ Detel, ${ }^{11}$ and Morel, ${ }^{12}$ who endorse two main claims on $\mathrm{H}$. On the one hand, they suggest that H6 is where Z17's new starting point is fully developed; ${ }^{13}$ but on the other hand, they also hold the view that H1-5 are a centerpiece of H6's solution, and so they urge to integrate these intermediate chapters within the full story told in $\mathrm{H}^{14}$

\section{METAPHYSICS Z17 IN THE “PHYLOGENETIC TREE” OF H}

In Z17 Aristotle takes another starting point ( $\alpha \lambda \lambda \eta \nu$ oĩov $\alpha \rho \chi \eta े v, 1041 \mathrm{a} 7)$ in his discussion on substance. Accordingly, the substance is principle and cause

${ }^{6}$ Ross 1924.

${ }^{7}$ Bostock 1994.

${ }^{8}$ Burnyeat 1984.

${ }^{9}$ Burnyeat 2001.

10 Gill 1996.

${ }^{11}$ Detel 2009.

12 Morel 2015.

${ }^{13}$ This is not to say, however, that these authors think that the story told by Aristotle in ZH comes to an end in H6; particularly Gill 1989 emphasizes that Aristotle's solution to the problem of unity is only reached in $\Theta 7$.

14 Burnyeat 2001, 71 claims: "H6 is the crowning moment of $\mathrm{ZH}$, where the reworking of form and matter in terms of actuality and potentiality at last makes it possible to solve the big problem left over from Z11, the unity of definition..." See also Gill 1996, 209: “[...] there is a pressing need for an investigation of $\mathrm{H} 1-5$ in their own right. What is the Project of these largely neglected chapters? How do they relate to the argument of $Z$ and prepare the way for H6?" Another common way to read $\mathrm{H}$ is to consider $\mathrm{H} 6$ in its relation to $\mathrm{Z12}$, and to discuss whether the solution to the problem of unity is valid both for definitions and material compounds (so do Steinfath 1996, Loux 1995, and Gill 2010). Two important works that illustrate the rather onesided focus on H6 are Gill 1989, 138ff and Harte 1996. The influential commentary on Z by Frede and Patzig 1988 took Z's argument as self-contained and as having an end in Z17. This is still the view in several books (Wedin 2000, Angioni 2008, and Lewis 2013), but see the opposite view in Loux 1991. Frede 1994 saw H mainly as a preparation for the next discussion on separate substance in $\Lambda 7$ and $\Lambda 9$. For a very useful discussion on Zetology see Galluzzo 2006. The (ongoing) turning point in the investigation on $\mathrm{H}$ took place in the present century by means of some books and commentaries. See, for instance, Burnyeat 2001 (who presents a brief commentary on $\mathrm{H}$, in which he rehabilitates $\mathrm{H}$ as the place in which $\mathrm{Z}$ 's theory reaches its fulfillment). Detel 2009 and Morel 2015 comment extensively on H. Morel 2015, 7-12 mentions current perspectives on $\mathrm{H}$. Important ongoing contributions on $\mathrm{H}$ include some (to my knowledge, still unpublished) presentations of Code, and papers (some of them also unpublished) by Seminara 2014 and Seminara 2018, Pfeiffer 2016 (who particularly highlights the program of H), Rapp 2018. (I warmly thank these colleagues for kindly having sent me and discussed their works on $\mathrm{H}$ ). Two further contributions on $\mathrm{H} 5$ and $\mathrm{H} 6$ were recently published in the same volume of Elenchos; see Baghdassarian 2014 and Delcomminette 2014. As for many other topics in the Metaphysics, Menn's still unpublished book is an important contribution to the discussion of $\mathrm{ZH}$ (see Menn, IIe). 
(1041a6-10). This is a new role for form (1041b8). Matter is, on the contrary, an element (1041b31) of the sensible substance. An important subsidiary thesis of $\mathrm{Z} 17$ is that hylomorphic compounds are genuine units -even though they are not immediate units like the very simple things (1041b9-10)- rather than mere heaps (1041b11-12). ${ }^{15}$ The form is the cause of the compound's unity, and it is joined to the matter. ${ }^{16}$ Aristotle disentangles the metaphysical structure of compounds by applying the why question to them. Compounds only seem to be simple things; yet, by considering them more closely, they are disclosed to show their very complex structure as made of a form that is predicated of a matter (see also H2, 1043a5-6). A further main assumption of Z17 is that form is irreducible to matter -this is what Aristotle tries to argue for in the final section of Z17 (1041b19ff) ${ }^{17}$ For Aristotle in Z17, thus, form is prior and is the primary

15 The immediate units are probably the forms -they are referred as essence and substance in these same lines. See Ross 1924, II ad loc., and Burnyeat 2001, 60. In 1041b9-10, Aristotle detaches compound things -about which one has to look for the why and the cause (1041a27-28, b5)- from immediate units - about which there is not inquiry, or one has to inquire

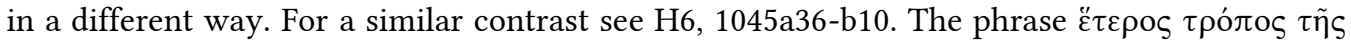
$\zeta \eta \tau \dot{\sigma \varepsilon \omega \varsigma}$ in 1041b10 is commonly translated as "in a different way" (so does Ross, similarly Burnyeat, Frede and Patzig) or "some method other than inquiry" (Bostock). Yu 1997, 132fn. 16 considers possible translations of this phrase as well as their consequences. The general thesis that simple things are indemonstrable is a main theorem drawn from Posterior Analytics (I 2-3), whose general distinctions about inquiry and demonstration (see also APo. II 1-2, 7-10) Aristotle applies to hylomorphic compounds in Z17. Burnyeat 2001 makes the suggestive remark that the term "form" is absent from Z17. However, expressions for essence like that of 1041b6 clearly make reference to the form; the nature and the substance (1041b27) of each thing are also references to it. On the contrary, as commentators unanimously remark (e.g. Morel 2015, 12, 23, 39 et passim), the modal vocabulary of potentiality and actuality -introduced for the first time at H1, 1042a28- remains absent from Z17.

16 On problems about this double unity -i.e. the unity of a compound and the unity of form and matter- see Lewis 1996.

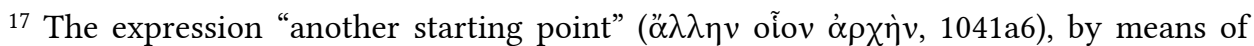
which Aristotle signalizes his new approach on form as cause in Z17, might lead us to believe that the entire discussion of the previous sixteen chapters is throw away at one stroke. This is not the place to discuss the controversial relation between $\mathrm{Z17}$ and Z1-16, but one should be aware of the quite obvious fact that whatever one thinks about it will have an impact on the significance held by the new approach to substance launched in Z17; and, in particular, it will have an impact on the meaning we think the thesis of form as cause has in relation to both Z17 and $\mathrm{H}$. Let me make here just a few suggestions on the controversial relationship between $\mathrm{Z} 17$ and Z's previous chapters. One may think that Z17 reintroduces the candidate for substance already examined in $Z 4$, i.e. essence, but it does so within the hylomorphic framework (provided by Z7-9). Accordingly, what is to be a house explains (i.e. it is the cause of) that certain materials constitute a compound of some sort. Such an approach to $\mathrm{ZH}$ would not limit, of course, book $\mathrm{H}$ to be a development of Z17's argument only (as, for instance, it is suggested by Gill 2006, 361; she claims indeed that the four candidates for substance examined in Z3-16 are plainly rejected in Z17). This approach would rather address (at least) some chapters of book Z as having a positive impact on H's discussion. As Detel 2009, 558 fn. 138 remarks, such a view fits better with the fact that H1's summary records the entire book $Z$ (with gaps). In this reconstruction of Z, one may put in brackets for a moment whether the chapters Z7-9 originally belong to book $\mathrm{Z}$ or they are rather -as commentators mostly think- later additions. The important thing is, however, whether Z7-9 help or not to move forward Aristotle's discussion in Z -I suggest, they do. The aporematic reading of $Z(Z 1-16)$ was favored by Code 1984 , who suggests that $Z$ is a 
object of the causal inquiry. However, there is an interesting passage in which Aristotle binds the causal inquiry, which seems to point exclusively to form as cause, to the matter. This could give us an idea of the intertwining between form and matter in causal inquiry:

[...] For instance, why are these <materials $>$ in that state a house? Because that which was to be a house belongs $<$ to them $>[\ldots]$ Thus what is sought is the cause of the matter, i.e. the form by which $<$ the matter $>$ is some sort of thing; and that is the substance $<$ of the thing $>$. (1041b6-9)

Let us now take a quick look at the explanatory model of the Analytics with which Aristotle works in Z17. In standard scientific explanations, one starts from a knowledge of the fact-for instance, that it thunders (or that some phenomenon is a thunder)-; hereafter, one asks for the cause of the fact -it is suggested, then, that the cause of that noise in the clouds is the extinction of fire. This is the general model applied by Aristotle in 1041b21ff: one knows that this is a human being or a house, and hereafter one tries to analyze causally the structure of these phenomena (1041b3) in that one seeks which is the cause of certain materials making a compound of some sort. At first glance, Aristotle's answer is quite obvious: inasmuch as the essence organizes or determines some matter, it is the cause of this thing here being something of some sort -for instance, the essence of a house is the cause that these bricks and stones constitute a concrete house (1041b1-8). The explanatory syllogism in Barbara with which Aristotle works out metaphysical explanations in Z17 could be reconstructed as follows: ${ }^{18}$

P1 Being a house belongs to the structure that is defined as protective building of humans and their properties;

P2 the structure defined as protective building for humans and their properties (i.e. what is to be a house) belongs to these bricks and stones arranged in a certain way; therefore

C being a house belongs to these bricks and stones arranged in a certain way.

much more detailed (than book $M$ ) examination of the twelfth aporia presented in B, i.e. the difficulty about whether the principles (or the primary substance) are universals or rather particulars. More precisely, according to Code Aristotle endorses the view that the principles and the primary substance (of sensible substances), i.e. the forms, must satisfy two conditions: the condition of determination and of particularity -which are proper to a tode $t i-$ as well as the condition of definability -that is proper to a ti esti. Also Gill 1989 takes Z as an aporematic book, but she grounds this view on the unsolved problem of the unity of composite substances -her main claim is that matter's independent contribution makes unity impossible in Z.

18 For the application of the explanatory model drawn from the Analytics to Z17's hylomorphic structures see Wedin 2000, 414ff; and for the reconstruction of the metaphysical syllogism, see Detel 2009, 538f. I thank Christian Pfeiffer for discussions on this topic. 
A possible interpretation of this syllogism claims that the first premise (P1) expresses the definition of house provided by the specific form (or P1 conveys what is to be a house); the conclusion (C) conveys the specification of the thing ("this thing or this stuff is a house"), which is obtained by means of the metaphysical predication of form to matter, which is expressed, in turn, in the crucial second premise (P2). As a result, in $\mathrm{P} 1$ there is a definition, in P2 there is the metaphysical determination by means of the predication of form to matter (metaphysical explanation that conveys the clue for the causal relation), and in $\mathrm{C}$ we get the classification of the compound by means of the explanation of the matter as constituent (bricks and stones are, i.e. constitute a house, and therefore this thing or this stuff here is (classified as) a house). So by means of an in depth analysis of the structure of the fact (i.e. an analysis of the thing that is called house), we can explain why this is a house: this thing here is a house (compound) because that specific arrangement (form) of bricks and stones (matter) makes these stuffs fit to accomplish the function defined by the essence.

Several difficulties are concealed in this syllogism. For instance, the syllogism does not clear up the following dilemma: either $(a)$ form and matter are two mutually independent components at the same level -but if it is so, then the compound's purported unity will be a problem, and, further, the compound will be something superimposed on its two components- or $(b)$ the compound is nothing but its form - but if it is so, then the matter will be redundant and the purported material feature of the sensible compound will be left unexplained. There is a possible answer to the first horn of this dilemma; it claims that form and matter are the same thing. However, if one endorses this solution, then one cannot really get a compound, but an entity made up of only one component -i.e. its form-, and this will bring one back, lastly, to the problem disclosed in the second horn of the dilemma -i.e. that matter is redundant. Whatever horn we choose to work out a possible solution, we seem to remain trapped in a dilemma: either we create the compound as a sort of third entity above the two components that remain mutually independent-according to $(a)$ - or we are forced to give up the composition of hylomorphic entities by reducing them to their corresponding forms -according to $(b)$.

These are precisely the difficulties book $\mathrm{H}$ aims to solve, as I will suggest. Beyond further problems involved in this syllogism, one should notice that at some point in Z17 Aristotle's argument is based on a crucial assumption that is left unjustified, since he takes for granted that the material parts of a compound make up a unified whole (1041b11-12). We do not find in the rest of the chapter (1041b11-33) any defense of this claim. Aristotle devotes the last section Z17 to maintain that form is irreducible to matter (and compound); yet, the unity assumption remains there unexamined. 
The way in which Aristotle gives support to the thesis of the irreducibility (and priority) of form in Z17 involves a reductio argument (1041b19-25), in which he holds that, unlike mere heaps, wholes do not dissolve together with the corruption of their parts (1041b14-16). This is striking, because heaps are Aristotle's favorite example for mere sums that lack a genuine unity. So the two claims -i.e. (1) the priority of form, for which Aristotle presents an argument in Z17, and (2) the unity of compounds, which is left unjustified- seem to be the front and back of Z17's bill. In his argument for the priority of form, Aristotle purports to show that wholes behave similar to syllables, in that they are something different from their parts or elements (1041b16-17). But still, the argument relies too much on intuition, since it is assumed that after the decomposition of heaps their parts remain in the same state they were before entering composition, whereas the parts of a whole, when the whole is destroyed, cannot survive as they were before. The reason for this dissimilarity would be that the nature of a whole requires that its parts must be radically modified just for performing the role they have to perform if they become parts integrated into the whole's functioning. On the basis of a similar reasoning Aristotle infers that any whole cannot be reduced to their elements or parts, in that we cannot give an account of what the whole is (i.e. its form) by mentioning the elements. Thus, by assuming that a whole must be something different from its parts, Aristotle endorses the view that what makes a whole what it really is cannot be either $(a)$ one further part of it, or $(b)$ something that is made up of several parts or elements (1041b19-33).

To sum up, there are two unjustified assumptions in Z17:

(1) Aristotle claims that the form is something different from the material parts, but this seems to imply that it is different from the whole too. He merely suggested that the form is the cause of the arrangement of the materials that constitute the whole. At most, this is an argument to distinguish the form from the elements, but it is not enough to distinguish the form from the whole. ${ }^{19}$

(2) He assumes, but does not explain, the distinction between the parts of a whole and the parts of a heap. This is certainly a crucial assumption in Aristotle's argument, since his claim that wholes are units, and so that they are not like heaps, relies precisely on that assumption.

It would be wrong to assume that these issues ceased to interest Aristotle after having completed Z17. In the following section I will suggest that he continues dealing with them in $\mathrm{H}$, and more precisely that in $\mathrm{H} 6$ he comes up with a remarkably economic and plausible justification of the two controversial assumptions he left unjustified in Z17, i.e. that (1) the form as cause is something

${ }^{19}$ Some interpreters hold that there is only a linguistic distinction between the form and the whole or the arrangement of materials. This is, however, a view I do not see reasons for accepting it. 
different from the compound and its material parts, and that (2) the material elements of a hylomorphic compound are tightly-fitted so that they make up a unified whole. Yet, the argumentative support for H6's compact solution is not in that chapter but in H1-5, to which we have to come back for arguments. More precisely, H2-3 justify the priority of form, and H4-5 do the same for the unity of the material compound. Before going back to examine these two duets (together with the summary of $\mathrm{Z}$ in $\mathrm{H1}$ ), let me briefly describe the finished shape taken by the Aristotelian material substance in H6, whose message can serves us as a guide to go into the examination of the detailed arguments of H1-5.

\section{H6'S SPECIFYING MODEL}

Given the short and compact expression of the way out of the problem of unity in H6 (1045a23-25), the suggestion that the argumentative support of that celebrated solution can be found in H1-5 only, may have some plausibility. H6 has plenty of allusions to previous discussions, ${ }^{20}$ and when it comes to convey its position, this pops up with no proper preparation; Aristotle's positive claims are merely framed by a criticism against Platonic assumptions on substance and composition (1045a16, b4ff). ${ }^{21}$

In 1045a7-22, Aristotle begins H6 by assessing the unity question in terms that clearly refer to Z12 and H3 (unity of definition and the parallel unity of number). Furthermore, it repeats the distinction between wholes and heaps first introduced in Z17. This is an important reference, since, taken together with the mention of the cause of unity for bodies (1045a11), it extends the question about unity from definitions to material substances and leads me to suppose that Aristotle works with one single model to explain both compositions. In the second section of H6 (1045a23-35), Aristotle contrasts his own position about unity to other Platonic-style alternative explanations (1045a16-22) which are likely to fail because they take the parts of compounds to be independent and complete things. This problem takes us back to Z13, where Aristotle denies that a substance can be a unit if it is composed of other actual existing substances (1039a3-14). In the next section (1045a36-b10), Aristotle compares unified

${ }^{20}$ For instance, 1045a9-10 refers back to Z17's treatment of parts and wholes/heaps; 1045a13-14 involves a further reference to Z4's discussion about the object of definition (essence) and the unity of it; this is followed by an allusion to Z12's examination of the unity of definition in 1045a18-20.

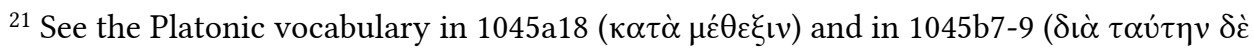

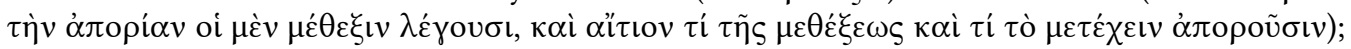
this is followed by the introduction of an alternative way of explaining union -which is also

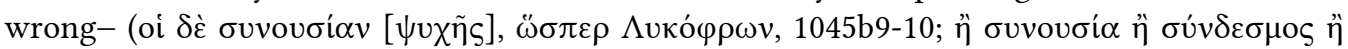
$\sigma u ́ v \theta \varepsilon \sigma ı \varsigma, 1045 b 13)$. Yet, probably, both positions share a common (Platonic) mistake, i.e. that of the independence (and actuality) of the parts of a compound, which Aristotle rejects in 1045b16-23. (I keep with Ross 1924 the last lines of the chapter; for a discussion see Morel 2015, 200-5). 
compounds, on the one hand, and things that are immediately one -absolute units were already considered in Z17 (1041b8-11). ${ }^{22}$ The last section of H6 (1045b11-23) reassesses the main topic of the chapter, i.e. the inquiry on the cause of the compound's unity, as it was already raised in 1045a8-10:

But, as it has been said, ${ }^{23}$ the last matter and the form are one and the same, the one potentially, the other actually; therefore, it amounts almost to the same to investigate which is the cause of the unity and of being one. For each thing is a unity, and the potential and the actual are somehow a unity. Therefore there is no other cause $^{24}$ unless there is something that moved from potentiality to actuality. $(1045 \mathrm{~b} 17-22)^{25}$

In the next sections of this paper, I will try to show that this final solution involves an explanatory model that is argued for only in the previous chapters of $\mathrm{H}$; but for now let me draw the outline of H6's main outcome. The different causal role of both components (form and matter) translated by Aristotle here in modal terms (actuality and potentiality) can guarantee the vertical or synchronic unity of a material substance. This is rendered possible thanks to the causal role played by the form that actualizes the dispositional properties of the proximate matter, and in this way it brings about the unified compound. Material substances are constituted by what Aristotle calls last or proximate matter ( $\dot{\eta} \dot{\varepsilon} \sigma \chi \alpha \dot{\tau} \tau \ddot{u} \lambda \eta, 1045 b 18$ ). This is the matter that results from the differentiation or specification of the preexisting matter by means of the form's causal role. Specifying the matter in that way implies that it now plays a functional role within the compound, and this new role implies, in turn, a radical change in the preexisting matter. The potential aspect of matter can be grasped in terms of the definition of motion or change provided in Physics III 1, 201a27-29 (a paraphrase of 201a10-11):

22 These immediate unities are contrasted to material wholes in the last line of H6

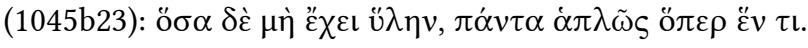

${ }^{23}$ See $1045 \mathrm{a} 23-24,1045 \mathrm{a} 29-30$

${ }^{24}$ Meaning that that there is no further cause of unity besides the two items already mentioned, i.e. the actual form and the potential matter.

${ }^{25}$ My translation. In 1045a30-31, Aristotle claims that in the case of individuals -which are subjected to generation and corruption- the essence and the efficient cause explain the actualization of the potentiality. Commentators mostly think that H6 focuses on particular compounds (so Charles 1994, 88ff); however, the problem raised there and its possible solution apply to general compounds as well. Detel 2009, 636ff rightly claims that Aristotle restricts his consideration to particulars only in the last lines of this chapter (1045b21-22). 
The <actuality $>$, then, of what is potentially -when being in actuality it is operating, not qua itself but qua changeable- is change. ${ }^{26}$

This definition states that what is subjected to change combines being potential

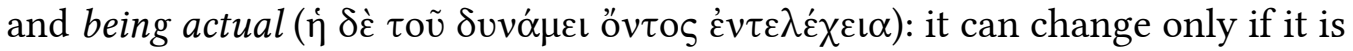
already something that is in actuality what another thing is in potentiality; so

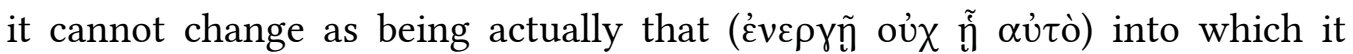
changes. For the context of Metaphysics $\mathrm{H}$ the definition of the Physics has a double implication. First, the preexisting matter must be located one step before the constituent (or proximate) matter that makes up the compound (i.e. that can already change into the compound). But second, that constituent matter, as far as it constitutes the compound (materially) -and it is subjected to change-, cannot be actually the same as what it makes up. As a consequence, the proximate matter, even if it is full-determined and, in a way, actual, cannot be a material constituent qua being actual (or it cannot change qua being already the thing

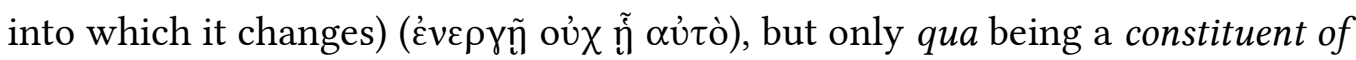
the compound (in other words, it cannot change but as being something changeable) ( $\left.\dot{\alpha} \lambda \lambda^{\prime} \tilde{\eta} \tilde{\eta} \kappa \iota \eta \eta \dot{v} v\right) .{ }^{27}$ Otherwise, we would face the problem of indistinguishability between the specified matter and the compound's form. ${ }^{28}$

Let me seize now up the impact that this consideration of the Physics can have on my reading of Metaphysics $\mathrm{H}$. The general definition of motion allows us to claim that within any single compound there is only one actualized matter -i.e. the constituent proximate matter that is suitable to perform the role required by the nature of the higher compound it makes up as matter. This is made clear in the Physics when in 201b5-8 Aristotle tries to pick out the time (and the conditions) in which something that is potential and can change can really exercise its potentiality:

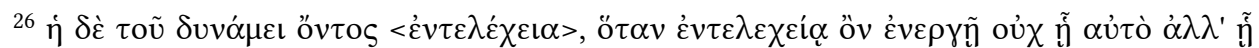

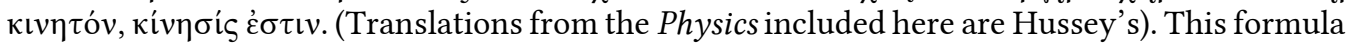
has been admirably discussed by Kosman 1969; for clarifications see also Hussey 1983, 58-62; Vigo 1995, 109ff defends the definition against the charge of circularity in that he rightly grants $\dot{\varepsilon} v \tau \varepsilon \lambda \varepsilon^{\prime} \chi \varepsilon \iota \alpha$ a non-procedural meaning.

${ }^{27}$ In the first account of motion in Ph. III 1 (201a10-11), this idea is expressed by a quaclause that must qualify 'actuality' (pace Hussey): "[...] the actuality of that which potentially

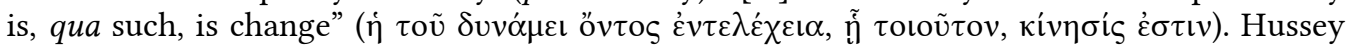
1983, 58 suggests to rephrase the qua-clause as follows: "The actuality-qua-potentially-being of that which potentially is." He elucidates the 'actuality-qua-potentially being' (which is meant to characterize the state of the changing thing as such) as an exercise (which is an actuality) of a disposition to change (which is potentiality). In short, the changeable thing changes in that it exercises its capacity to change (or: it is changeable as such and in actuality in that it (actually) changes); see Aristotle's example for change with building in 201a16-18: "[...] when that which is buildable is in actuality, in the respect in which we call it such, it is being built, and this is the process of building [...]" (

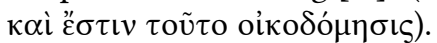

28 This is Ackrill's problem (see Ackrill 1972/73). 
[...] change occurs just when the actuality is this actuality, and neither before nor after (201b6-7).

Thus, change occurs only during the process in which bricks and stones are changed into a house. ${ }^{29}$ As I have stressed, only the proximate matter is potentially the form of the compound, in that such a matter involves the necessary disposition to constitute (or turn into) the compound's form. For that matter to be potentially the form means that the matter's actuality consists in its potentiality to be (or constitute) that form. So the Physics's teaching about the actuality of potentiality permits us to pick out the constituent matter as that stuff that has the necessary disposition to turn into the form. This is implied in the Physics when Aristotle claims that for some matter to be potentially the form means that such a matter has already the disposition to turn into that form -or in Aristotle's own wording in 201a28-29: the matter's being in actuality-qua-

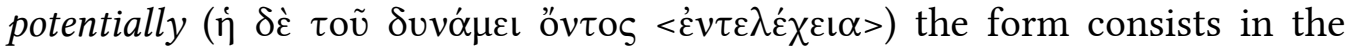
exercise of its disposition. ${ }^{30}$ The Physics excludes, therefore, that the matter that is the constituent of a house can only be the matter located one step back from the required determination (or potentiality to be a house). Now, as far as the proximate matter (bricks and stones) only has the required disposition (potentiality) to constitute the higher compound (the house), this teaching has also an important consequence for the compound's unity and its single performance, since if the lower levels of matters (i.e. the matter's that are not constituent) do not survive actually within the functionally determined proximate matter, ${ }^{31}$ then there will be no risk of finding many layers of actualized matters (endowed with possibly contradictory dispositions) coexisting in a single compound.

With the help of the modal translation of the causal model introduced in $\mathrm{Z} 17$, Aristotle can manage in $\mathrm{H}$ to harmonize vertical (or synchronic) and horizontal (or diachronic) unity. In fact, the dispositional properties of the preexisting matter persist within the compound only as far as they are functionally specified as the constituent material parts of the compound. As I suggested, this persistence in change helps to avoid the problem of actual layers of matter. But once the compound is dissolved, those dispositional properties can become actual again. For instance, once an organic body is corrupted, their constituent parts are radically altered, and as a consequence of that radical change they

\footnotetext{
${ }^{29}$ See Vigo 1995, $116 \mathrm{f}$.

30 See Hussey 1983, 61.

31 This is prevented by Aristotle's cautionary tone in its clarification of the qua-clause in
} Ph. III 1, 201a29-31: "[...] the bronze is potentially a statue, but yet it is not the actuality of bronze qua bronze that is change." And then: "the actuality of potential, qua potential, is

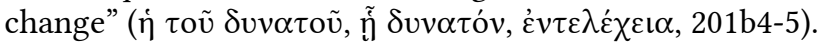


become actual, i.e. they actualize previous dispositions. For example, the bones and the sinews, which were radically changed to become parts of a hand, recover -once this hand is corrupted- their own material forms, and so the process of corruption gives rise to actual compounds (bones and sinews), which are what we called the preexisting matter of a hand. But we must also emphasize that generation involves a radical change in the preexisting matter, so that the form of that matter cannot survive, i.e. the forms of the bones and the sinews perish when they become constituent parts of a hand. Once again, the minimal condition for persistence -established by the persistence of the dispositional properties actualized as constituent matter of a higher compound- does not result in layers of actual matter (i.e. forms) within a higher compound.

These complex details are compactly conveyed in the final message of H6 quoted above, which states that the matter of a compound is the same as the form, but only in potentiality. So the matter does not enter into a compound with its own form unchanged, because its potential being refers to (i.e. depends on) the form (of the higher compound), which remains being the only actual factor within the compound. In sum, on the one hand, the vertical unity of a compound is guaranteed by the actualization or specification (brought about by the highest form of the compound) of the lower material forms that preexist to the compound. And on the other hand, the dispositional material properties that persist in the higher compound guarantee the horizontal unity by establishing a minimal but sufficient continuity in substantial change.

There is still the problem of unity that should be solved by H6's specifying model. Composite substances must be strong unities (i.e. a whole, not a heap, in the words of Z17). But Aristotle holds that we cannot get a strong unity from merely potential parts. In Z16, 1040b5-26, he demotes the parts of the animals and the elements as to the substance range precisely because they cannot exist separate or build a unity on their own. Thus, they are taken as merely potential components. For the present context, this means that potential parts cannot ground a strongly unified compound. But, isn't it said by Aristotle in H6 precisely that matter is potential? So how could Aristotle avoid that the potential status of matter lastly results in a demotion of the unity of compounds in H6? To solve this difficulty, the model of $\mathrm{H} 6$ tries to harmonize the actuality of the proximate matter with the compound's strong (i.e. vertical) unity. This is no longer a problem for Aristotle in that he manages to explain the constituent matter as the only actual existing stuff within the (single) compound. That matter is, as he triumphantly claims in H6, the matter that, as a result of having been actualized by the form, is one and the same with that form.

Let me close this section by stressing some points. Since $(i)$ by means of H6's specifying model, the proximate matter is explained as the only actualized constituent of the composite substance, Aristotle can hit two targets with one 
shot by justifying unity and substantiality of material compounds. Further, (ii) by being potentially the same as the form, the proximate matter is essentially what the form is. But (iii) at the same time, since form and matter have different explanatory responsibilities, they cannot be one and the same without restriction (i.e. the problem of indistinguishability of form and matter). ${ }^{32}$

\section{EXPLORING MATERIAL SUBSTANCE IN THE "SHALE” OF H1-5.}

\section{H1 AS A SUMMARY AND TRANSITION}

I have claimed that Aristotle did not fully justify his two main theses in Z17. In fact, (1) he did not explain how the causal role of form does account for its being different from the compound and its matter, and further (2) he does not manage to fully clarify the conditions that must be fulfilled by material parts to constitute a unified whole rather a mere heap. I have also suggested that H6 draws a line under the argument that develops a complex explanatory model through which, one can guess, Aristotle thinks that Z17's two remaining difficulties can be solved. To put it simply, by means of H6's specifying model, Aristotle holds (i) that the (highest) form functionally specifies the (proximate) matter. Thus, as a consequence of form's explanatory role, (ii) he is able to justify in H6 the priority of form and its distinction from both the compound and its matter. So, (iii) Aristotle gets a unified whole, eventually, because the material parts are fully determined by the form of the higher compound they constitute -i.e. the materials that become constituent parts of a higher compound do not keep their own forms and are neither independent nor actual.

H6's elegant solution to Z17's problem is very appealing; but in the chain of the argument leading to the solution I sketched above almost every link is still missing. Fortunately, those links can be found in H1-5. I would like to begin my reconstruction of that chain by considering H's first link in chapter 1, which introduces the role of matter as potentiality. This link is then interrupted for a while in H2-3, where Aristotle shifts to form as actuality, but it is shortly after picked up in H4-5. These are the links, roughly speaking, of H's big project. ${ }^{33}$

${ }^{32}$ Aristotle's position in Metaph. H entails as a further consequence that the strong unity of compounds requires that the predicative relation between form and matter cannot be accidental. -Being said of something different is the predicative structure of accidental relationship, according to Z4, 1030a4. The strong unity of material compounds is resisted by Loux 1991 and Loux 1995 with the argument that the matter is predetermined and, therefore, its unity with the form cannot be a necessary one. This sort of reading is classified by Rhenius 2005 as "traditionalism." In many aspects of the interpretation of H6 I agree with Detel 2009, 621-654 (see in particular 644ff).

${ }^{33}$ Detel 2009, 642, stresses the importance of H1-5 for the whole argument of the book: "Der wesentliche Grund dafür ist, dass man den einheitlichen systematischen Zugriff auf dieses Problem in den Büchern VII und VIII verkannt und den Beitrag der Kapiteln VIII 2-5 unterschätzt hat.” Even if Gill 1996, 217 undertakes a reappraisal of H1-5, she maintains her 
The first problem interpreters face in $\mathrm{H} 1$ concerns the scope and meaning of the summary Aristotle announces in 1042a3-4. So I will start from that issue. Let us first take a look at the distribution of topics in the chapter. The summary spans from $1042 \mathrm{a} 3$ to $1042 \mathrm{a} 24$, and it contains two clearly distinct sections. In the first one (1042a3-5), Aristotle draws some conclusion from what has been said; he refers, probably, to the previous investigation when he claims that the inquiry dealt with the causes of substances. It is an open question for interpreters whether this is really a reference to the discussion on substance in book $Z$, and more particularly to Z17's innovative starting point that makes form a principle and cause or it rather involves -within its vision radius- a wider scope of investigations presented in other books of the Metaphysics. I will discuss this alternative here below, but for now I should be content with warning in advance that this can be hardly taken as an uncontroversial reference to Z17, since Z17's thesis, as I said, is that substantial form is cause. This seems to be a bit more specific than saying that, as Aristotle does in 1042a5-6, the inquiry was about the causes, the principles, and the elements of substances. In the second section of this summary (1042a6-24), Aristotle makes a reference, in a closed synthesis, to the whole discussion of book Z (1042a13-24). In 1042a6-12, he further lists (he did likewise in Z2) different entities that are (commonly or exceptionally) held to be substance. In two short passages (1042a12 and 1042a22-23), Aristotle mentions Ideas and mathematical entities as things that the Platonists take to be substance, and he further postpones discussion about these entities, which is probably found in books MN. Afterwards, in 1042a24, Aristotle picks up sensible substances, which, as it was already said in 1042a6, are commonly held to

view that these chapters do not offer a definitive solution to the problem of unity, which she only finds in $\Theta 7$ (with an important anticipation in H6): "Only in $\mathrm{H} 6$ does Aristotle offer a viable framework for a solution he develops in Metaphysics $\Theta$." On the role of matter in substantial generation she claims: "For although matter is potentially but not actually the product, it is also something actual in its own right. And if this actual subject constitutes the generated object, as the letters A and B constitute the syllable 'ba', the subject is existentially prior to both the form and the composite, since the form is a property of it, and the composite is merely the compound of that subject characterized by that property." (Gill 1996, 220f). So she raises the following dilemma: either $(a)$ matter is already some sort of thing, so that form is nothing but a property added to (or accidentally predicated of) the subject -therefore, matter is both logically and existentially prior to the form and to the compound-; or (b) matter cannot be taken as being something definite, so that it cannot be explained which is matter's real contribution to the compound. But, being that so, we can dispense with matter by giving an account of the material compound. (Gill suggests that this mirrors the state of matter when something is corrupt, i.e. the material substrate in corruption is deprived of any form.) Needless to say, option ( $a$ ) does not permit to get a strong unity of compounds, and option $(b)$ leads to disregard any matter and to reduce a compound to its form. Gill's suggestion on Aristotle's theory of matter in H1-5 is that he remains trapped there in a conception that holds matter to be something actual or a this (a tode ti). She relies heavily on this assumption to bring grist to her mill, i.e. to see $\mathrm{ZH}$ as mainly faulty solutions to the problem of unity. Detel 2009 favors a much stronger rehabilitation of H1-5; in fact, he stresses that H1-5 (but also Z12, Z14, and Z17) prepare the positive solution of $\mathrm{H} 6$, whose brief message can be fully assessed only against the backdrop of the previous detailed arguments. For a convincing criticism of Gill's general reading on $\mathrm{H}$ see Seminara 2018. 
be substances. After having declared that sensible substances are those having matter, Aristotle heads for a brief consideration that, interestingly enough, moves around the limits of Z3 (1029a2-5), since he claims that substances can be subject according to three different ways: either as form, or as matter, or as compound (1042a26-30). Notice that already in 1042a27-28 he describes matter in a way -which is probably familiar to Aristotle's audience and readers- that, however, does not match his presentation of matter in Z3. In fact, Aristotle introduces matter in $\mathrm{H} 1$ as a this (tode ti), not yet as something in actuality but rather as a this in potentiality. ${ }^{34}$ This last claim is the right transition to the later focus on matter that dominates discourse up to the end of the chapter (1042a32b8). But, contrarily to the result reached in Z3, 1029a27, Aristotle suggests here that matter is substance too; more precisely, matter is substance as subject of changes (among them, substantial change comes first). From this last section of $\mathrm{H} 1$ and the beginning of $\mathrm{H} 2$ (1042b9-11), we can obtain the delimitation of the main topic of book $\mathrm{H}$ : it is an investigation about material substance, or about the substance of the sensible things, which covers both matter (which is substance in potentiality) and form (which is substance in actuality). ${ }^{35}$

One central remaining issue in the summary is whether Z17 is collected or not. It may be awkward to give a plain negative answer to that question, if we assume, along with most interpreters, that $\mathrm{H}$ takes its starting point from Z17. Yet, I suggested that 1042a5-6 cannot be taken as a precise reference to Z17. So if Z17 must be present in H1's summary, how is it there? I think, probably the best way to approach this difficulty is with the help of Burnyeat's reading of 1042a3-4. Burnyeat stresses that the selective summary of H1 clearly indicates which topics of $\mathrm{Z}$ Aristotle wants his audience and readers to have in mind by bringing his next discussion in motion. Burnyeat also mentions that the non-exhaustive character of the summary squares with a non-stenographic record of book $\mathrm{Z}$, and that this character is balanced under the assumption of a well informed reader, who already knows a lot about first philosophy. So, while other commentators evaluate the absence of any specific mention of Z17 in H1's summary as a gap (so Bostock and the Londinensis), Burnyeat claims, on the

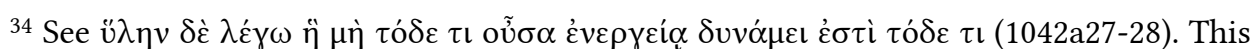
is repeated in $1042 \mathrm{~b} 10$. It leads us to think that H1's modal thesis on matter as potentiality is anticipated by the clarification of material parts as potentialities in Z16, 1040b6-14.

${ }^{35}$ Bostock 1994, 248-50 lists the arguments of $Z$ that are present in H1's summary as well as those absent from it. He suggests that all chapters of $\mathrm{Z}$ mentioned in H1's summary were part of Z's first redaction, to which some other were later added; precisely these ones would be missing in H1's enumeration. For another list of passages of $Z$ considered in H1's summary, see Burnyeat 2001, 62f. Burnyeat means (as already the Londinensis did) that H1's summary is a synthesis of the actual Z (excepting Z7-9 and Z12), and that it summarizes the discussion but not the results of Z. Similarly, Gill 1996, 212. On her part, Gill 1996, 214 suggests that the selective summary of $\mathrm{Z}$ in $\mathrm{H} 1$ reflects Aristotle's strategy to put in brackets all other chapters of $\mathrm{Z}$ that do not directly lead to Z17's new start. So she reads H1's summary as putting forward the discussion of Z17. 
contrary, that the purported absence of Z17 is reasonable, since the very character of the summary focuses on Z's discussions without mentioning its proper positive contributions. This approach to the summary allows Burnyeat to make a crucial suggestion that has an important impact on our reading of book $\mathrm{H}$. For Burnyeat, the summary of $\mathrm{H} 1$ should not be seen as a conclusion of Z's argument -as we are frequently led to think under the influence of most translations of

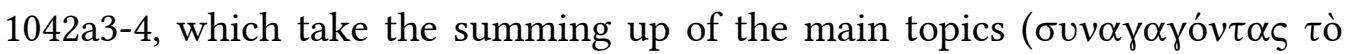
$\kappa \varepsilon \varphi \alpha \dot{\alpha} \lambda \alpha \iota v$ ) as if, with this summary, we could get the conclusion of $Z$ ( $\tau \dot{\varepsilon} \lambda$ os $\dot{\varepsilon} \pi(\theta \varepsilon \tilde{\imath} v \alpha \mathrm{l}) .{ }^{36}$ So Burnyeat uses his opposition to the common translation of these lines to positively explain the absence of Z17 in H1's summary. One main outcome I would like to stress in Burnyeat's reading of 1042a3-4 is that it makes it possible to recover H1-5 as the continuation of Z17's discussion, and perhaps even as its completion, since there are no grounds for assuming that Aristotle could have intended the summary to put an end to Z17's discussion.

This approach to the summary differs significantly from current assessments not only of $\mathrm{H}$ but also of $\mathrm{Z}$. We may wonder, however, whether the mere restitution of the grammar of 1042a3-4 will suffice by itself to support such a large change of mind on $\mathrm{ZH}$ and, more particularly, to decide the dispute about

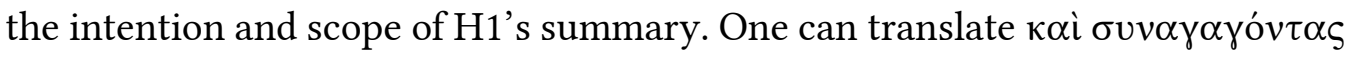

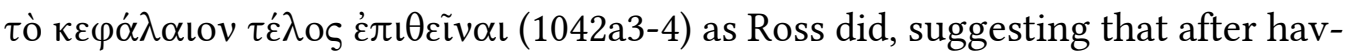
ing collected the main topics we put an end to the investigation about substance, yet without assuming therewith that the end we aim to put to this investigation is already reached at the end of the summary. In other words, there is no obligation, almost on whichever translation of the text, to make the end of the summary coincide with the end of the previous investigation. ${ }^{37}$ If this is so, there is no need to assess H2-5 (including the last section of H1) as a mere set of supplementary afterthoughts on $\mathrm{Z}$, which are added once the summary

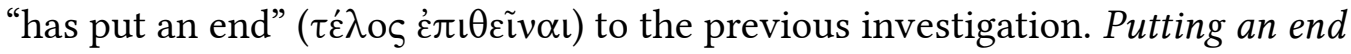
may perfectly pick out a fixed point ahead. In that case, the summary would

${ }^{36}$ Burnyeat 2001, 65-8. It may be convenient to quote right now this text, which I will

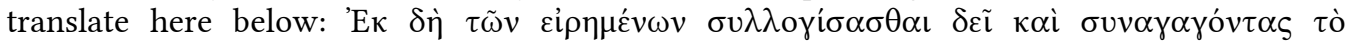

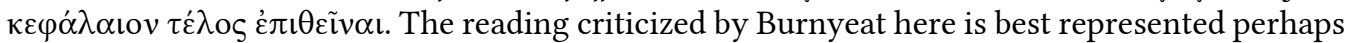
in Ross's translation: "We must draw our conclusions from what has been said, and sum up our results, and put the finishing touch to our inquiry." (emphasis added). Burnyeat tracks this reading to the Latin translation of Bessarion. One may guess that Bostock's interpretation of $\mathrm{H} 2-5$ as a set of isolated notes and appendices on $\mathrm{Z}$ heavily depends on this sort of reading of the first lines of H1. So, Bostock can assume that H1's summary closes Z, and what follows can be only a mere set of supplementary notes. See Bostock 1994, $259 \mathrm{f}$.

${ }^{37}$ In spite of his general reading of H, Bostock 1994 makes a better sense of this text in his translation: "Now we must bring together what has been said, draw our conclusions, and so bring the enquiry to its completion." (emphasis added). For a detailed commentary on these lines and the summary see Morel 2015, 82ff. Pfeiffer 2016, 3 points to the topics mentioned in $\Theta 1$, 1045b27-32 to suggest that the investigation announced in the summary of H1 is only completed by the end of the book. However, $\Theta 1$ does not provide any specific mention of the subjects covered in H. On this, see Ross 1924, II 240 and Makin 2006, 17. 
mark a pause in the development of the argument of Z17 and, at the same time, a transition towards its completion to be reached at some point in $\mathrm{H}$ (perhaps in H6). In the end, this suggestion is compatible with Burnyeat's point: the con-

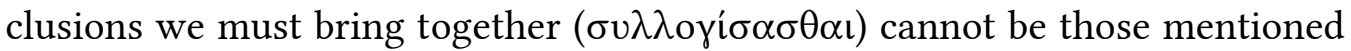
in the summary, but rather those we have to reach along the road of $\mathrm{H} 2-5 .{ }^{38}$

Let me now propose a working translation of H1, 1042a3-4:

From what has been said, at this point, we must draw the conclusions and bring < the inquiry > to its completion after having collected the main topics.

The next lines cannot be undoubtedly taken as referring to Z17's very specific inquiry about form as cause and matter as element of the compound:

Now, it is already said that we inquire about the causes, the principles, and the elements of substances (H1, 1042a5-6)

These lines can be a much more general reference to the objects of inquiry of first philosophy, as this is defined in Metaph. Г1-2 and E1. ${ }^{39} \mathrm{I}$ am satisfied with having made plausible that, if $\mathrm{H} 1,1042 \mathrm{a} 4-6$ was intended as a reference to $\mathrm{Z} 17$, this mention does not honor enough the importance of Z17's new point of departure and thesis. If the present interpretive suggestion on H1's summary is accepted, then Burnyeat's solution turns out to be very appealing. Since he explains the omission of Z17 as a mere fact depending on the character and purpose of the summary, it is a pause of $\mathrm{Z} 17$ and a transition to $\mathrm{H}$ which continues from 1042a24 on. That is simply why Z17's conclusion is omitted in the summary.

Let me round off this section by mentioning the main outcomes of the above sketched reading. A remarkable consequence I accept here is that, assuming that $\mathrm{H}$ is the completion of $\mathrm{Z}$ does not amount to a disqualification of $\mathrm{Z}$ either as to its argumentative development or as to its conceptual and theoretic apparatus. It certainly results in turning over the significance of these books as regards Aristotle's achievements and solutions about the problems of his theory

38 "Now it becomes clear that the summary is a prelude to the completion, not the completion itself. [...] The completion of $\mathrm{Z}$ is the rest of $\mathrm{H}$." Burnyeat 2001, 66.

${ }^{39}$ Z17's specific point of departure is signalized as follows: "Since the substance, then, is a principle and a certain cause, we must start from that point." (Z17, 1041a9-10). Ross 1924, II 226 assumes that H1, 1042a4-6 makes a general reference to Z1. But Burnyeat denies that these lines can refer to $Z 1$ and suggests instead that they presuppose the inquiry of E1 (see 1042a5-6 with 1025b3-4), Г1 (1003a21-22, a26-27, a31), and Г2 (1003b18). 
of material substance in the central books of the Metaphysics. This evidently involves a rejection of the common view that considers $\mathrm{Z}$ as Aristotle's final word on substance in the central books. ${ }^{40}$ It finally turns out that reading the scope of the summary of $\mathrm{H} 1$ like Burnyeat did will require reading $\mathrm{Z} 17-\mathrm{H}$ in a straightforward linear way. ${ }^{41}$ However, it is important to note that the general reading of the summary, which takes it as a pause of Z17 and a transition to the next chapters of book $\mathrm{H}$, cannot decide the issue as to the intrinsic qualities of the completion of $\mathrm{Z}$ provided by book $\mathrm{H}$. In fact, even among interpreters that are sympathetic to rehabilitating $\mathrm{H}$ as a whole, there are heavily different views on the book's real contribution to Z's theory of substance. Let me here present mine.

\section{H2: THE PRIORITY OF FORM AS ACTUALITY AND ITS SPECIFICATION THROUGH THE DIFFERENCES}

The first two links that constitute the big chain of H1-5 are H2-3. H2's first lines (1042b9-11) help to tie together H's general argument by means of one of the most important links of the chain of this book, i.e. the distinction between form as actuality and matter as potentiality. In H1, 1042a23-b8, Aristotle focuses on the main topic of this book, i.e. sensible substance (1042a23), which is made of matter (1042a26). There, he takes up one main criterion, drawn from Z3, to mark off substance, i.e. that substance is subject (1042a26). He repeats, thereupon, which entities could play the role of a subject: the matter -which is swiftly clarified as being something definite (or a this) only in potentiality but not in

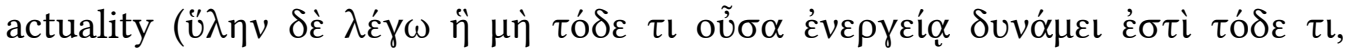
1042a27-28)-, next, the form, and, finally, the compound (1042a26-30). ${ }^{42}$ From

40 This is the view of Frede and Patzig 1988; the contrary opinion is held by Burnyeat 2001, 68: "For the map now shows Z1-16 as preliminary to Z17-H." Among interpretations that tend to deprive $Z$ of weight, I count those emphasizing (rather unilaterally) the aporematic feature of Z's arguments. This is another common view on Z I do not endorse.

${ }^{41}$ Burnyeat links the linearity issue to the two levels; accordingly, the linear argument of $\mathrm{H}$ would stand at a metaphysical level, whereas the non-linear $\mathrm{Z}$ would be at a logical level (firmly established at Z4). However, if it is true that Z17's new starting point is not broken off the trunk of $\mathrm{Z} 1-16$, then it will be at least feasible to think of $\mathrm{H}$ as a completion of the entire book Z, rather than to restrict that completion to be exclusively a further development of Z17's positive results.

${ }^{42}$ It may be convenient to sketch, at least, how I see $\mathrm{Z3}$ in relation to $\mathrm{H}$. I hold that a main result of $Z 3$ is that matter as it is there conceived, i.e. as a sort of residual substrate lacking any determination (according to the outcome of the thought experiment in 1029a11-26) cannot be substance, if it is true that substance, besides being a subject, is separate and something definite or a this (1029a26-28). This already negative result makes hardly acceptable a reading like that by Devereux 2003, who claims that Z3 is the result of a new redaction written only after H's new views on matter as potentiality. Not a vestige of such a modal conception of matter -which is precisely the point of departure in the argument about matter in H1 (1042a2728) and H2 (1042b10) - can be found in Z3, much less of the hierarchical conception of proximate matter developed later in H4-5. Z3's diagnosis on matter -which is not the same as saying that 
1042a32 onwards Aristotle specifies different ways in which matter can be subject (according to the change classified under the different categories), the first of which corresponds to the matter as subject of substantial change (1042a58). ${ }^{43}$ Similarly to the opinion recorded in Z3 (1029a32), Aristotle reflects in H2 (1042b9-10) the common view according to which matter must be substance in some way. Perhaps because there is a general agreement on this view, he postpones its discussion and devotes his first more detailed examination to the other thing that is said to be substance (as subject), i.e. form. Form as actuality will be the topic of H2-3. By the end of H2 (1043a26-28), Aristotle highlights the topics of the chapter: he wants to have dealt with which is the sensible substance and

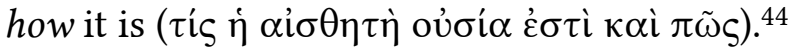

At least a few words should be said about the controversial lines of $\mathrm{H} 1$, 1042a32-b3, on the basis of which Gill built her dilemmatic reading of the contradictory position of matter in $\mathrm{H}$ (i.e. as a complete substance and as a potential substrate). ${ }^{45}$ The problem is to reconcile two apparently contradictory descriptions of matter found in H1, i.e. as potential being in 1042a28, and as an actual substance in 1042b3. Seminara concentrates his objections against Gill in the reading of Aristotle's description of the subject of generation and corruption in 1042b1-3. In particular, he claims that we can escape from Gill's dilemma by

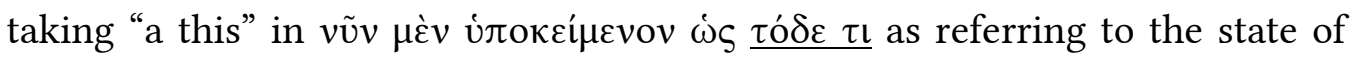
matter in "the end of the process of generation," where the matter, having at that time its own form, is a this. ${ }^{46}$ In that way, Seminara tries to reconcile the actuality of matter involved in the qualification $\tau$ ó $\delta \varepsilon \tau \iota$ with the potentiality

it is on Aristotle's own position - implies rather a flat matter deprived of any dispositional properties and located at the bottom, which can hardly make room for proximate matter. Morel 2015 , 30, 32f holds a slightly different view on Z3; he tends to make Z3 and H4-5 compatible on that score. So he writes (referring to $\mathrm{H} 4$ ): "L'attribution à la matière du statut de substance n'est donc pas un incident de parcours, une expression proposée 'en passant': c'est le premier temps d'un changement de discours, par rapport à Z3, que $\mathrm{H} 2$ y $\mathrm{H} 4$ vont confirmer. Ce changement de discours ne signifie pas pour autant changement de doctrine: plutôt un raffinement de la doctrine telle qu'elle est exposée en Z3.” Morel 2015, 35.

${ }^{43}$ To refer to the matter involved in substantial change, Aristotle resorts to the unusual

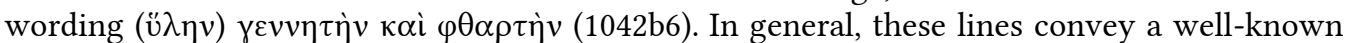
doctrine from $P h$. I 5-9 and GC I 4, to which Aristotle refers in 1042b8. But it is hardly possible that $\mathrm{H} 1$ conveys all what Aristotle has to say about matter. This passage reflects, rather, a

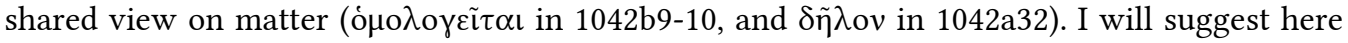
below that H4-5 presents a more fine-grained view about matter than that sketched at the end of $\mathrm{H} 1$.

${ }^{44}$ In Z3, 1029a32-34, Aristotle emphasizes that it is difficult to know how form could be substance as subject; next, in Z4-6 he goes on to inquire about the form in those entities that are commonly held to be substances, i.e. sensible things. Taking that into account, $\mathrm{H} 2-3$ are likely to be seen as a programmatic continuation of the discussion on form as substance launched at the end of Z3 (and perhaps continued as a way of preparation in Z4-6). Besides, H2, 1042b10-11 can be understood in relation to Z3, 1029a32-34 (with the addition of the modal vocabulary).

45 Gill 1989, 86ff.

${ }^{46}$ Matter not having yet acquired the form during the process of generation and thus not being $a$ this is standard theory; see $P h$. I 7, 191a10-11. 


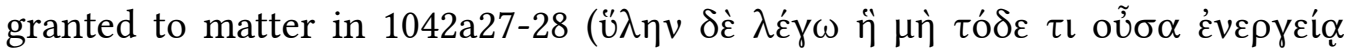

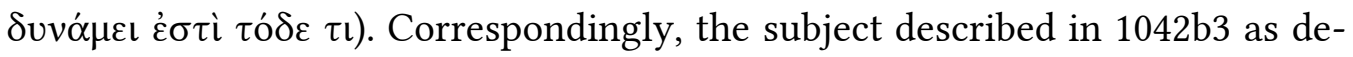
prived of a positive character or form is the matter at final time in the process of corruption. ${ }^{47}$ Seminara's is a thinkable option both to Gill's dilemmatic reading of these two passages and to Ross's way out, which consists in stating that the subject mentioned in $v \tilde{v} v \mu \dot{\varepsilon} \nu$ vं plete substance that undergoes the process of destruction, whereas the subject

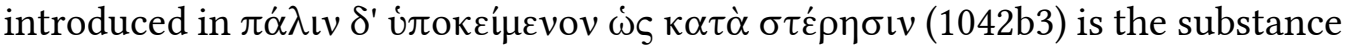
which underlies generation, i.e. the matter qualified by the privation of the form (acquired later as a result of generation). ${ }^{48}$ On his part, Morel remarks on these lines are, to say the least, salutary: calling the subject involved in generation a $\tau$ ó $\delta \varepsilon \tau$ ı does not necessarily mean (as Gill assumes and Ross's way out tries to avoid) that it is an actual being. ${ }^{49}$ So Morel's remarks -which I would accept here- promote the idea that the matter involved in generation can still have some degree of determination (since it is, in the end, something that has a form, like bronze), without being obliged to pay the price of counting that matter as an individual or complete substance. ${ }^{50}$ According to this suggestion, the subject involved in corruption could be qualified as $\omega \varsigma \kappa \alpha \tau \dot{\alpha} \sigma \tau \dot{\varepsilon} \rho \eta \sigma \iota v$ in that the material subject that undergoes destruction is deprived of its former dispositional properties. ${ }^{51}$ This is a reading of $1042 \mathrm{~b} 1-3$ that is consistent with the general interpretation I aim to present here. ${ }^{52}$

But let me turn now to H2. This chapter helps to specify the role of form as cause and to explain form's actuality by means of the differences ( $\delta\llcorner\alpha \varphi \rho \rho \dot{\alpha} \varsigma$, 1042b12, b32). Against Democritus - who is praised nonetheless for having introduced the idea of the differences-, Aristotle emphasizes that there are many differences (1042b11-15). He uses this idea to clarify how form specifies different materials. So Aristotle gives concrete expression to the suggestion that form must be understood in relation to matter in that form actualizes the matter's dispositional properties: in reference to a piece of wood, the difference that consists in being located above the door specifies this matter in a way that is explained by what a lintel is. But another difference -that of being located at the

47 Seminara 2018, 102-5.

${ }^{48}$ Ross 1924, II 227 reads these lines in a chiastic way.

${ }^{49}$ Morel 2015, 99.

50 Similarly Pfeiffer 2016, 7: "Die falsche Annahme, auf der die Interpretation von Gill wie auch Ross basiert, ist, dass der Ausdruck ,bestimmtes Dies' gleichbedeutend mit ,bestimmtes Dies der Wirklichkeit nach“ ist. [...] Auch ein dem Vermögen nach bestimmtes Dies ist ein bestimmtes Dies."

51 This does not mean that the material subject undergoing destruction is deprived of

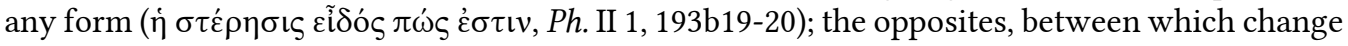
takes place, are two relative features or forms ( $P h$. I 7, 190b30-32).

52 See my interpretation of $\mathrm{H} 5,1044 \mathrm{~b} 36-1045 \mathrm{a} 2$ by the end of section 10 (which is generally in line with Seminara 2018, 107). 
bottom of a door- specifies the same matter in a different way, so that the resulting compound is explained as threshold (1042b15-31).

We can advance on this view by focusing on two main outcomes of $\mathrm{H} 2$ that confirm that in that chapter Aristotle programmatically develops Z17's thesis about form as cause. The first relevant outcome of $\mathrm{H} 2$ concerns the differences. Indeed, they help to specify the causal role of form in view of the kind of matter that is arranged or organized by the form: ${ }^{53}$

From this it is then clear that, since the substance of a thing is a cause of its being, it is among these < differences> that we have to inquire what the cause of the being of each of these things is. $(1043 \mathrm{a} 2-3)^{54}$

The second germane outcome of $\mathrm{H} 2$ to be considered here depends in a way on the former, but it helps to clarify the relational notion of form, which was already involved in the claim of Z17 (1041b5-6) that states that whenever we raise the question why (about some hylomorphic compound), we include matter in our question. This thesis matches the following passage of $\mathrm{H} 2$ :

From this it is then clear that for a different matter the actuality and the formula are different too: in fact, for some $<$ materials $>$, it is the composition, for others, the mixture, and even for others some other <of the differences> that have been mentioned. $(1043 \mathrm{a} 12-14)^{55}$

What Aristotle suggests here is that we must describe the causal role of form in a much more detailed way than merely saying -as in Z17- that the form is cause and principle; we must specify, as he urges now, the form in relation to the matter it arranges. Precisely this closer description of the causal role of form is

53 The differences of $\mathrm{H} 2$ are not the differentiae of Z12 (1037b19, 20, 22 etc.). However, I agree with Rapp 2018, 8 that the well-known division of a genus in differentiae resonates in the $\delta \iota \propto \varphi о \rho \alpha$ of H2: the differentiae specify a (determinable) genus, and similarly the differences specify the form (generally taken) in its particular relation to a given portion of matter.

${ }^{54}$ Bostock's translation (modified).

55 In H4, 1044a27-29, Aristotle makes a similar claim. However, while in the passage of $\mathrm{H} 2$ Aristotle claims that there is a correspondence between different forms (or acts) and different materials, in $\mathrm{H} 4$ he suggests that the matter is functionally determined (as to its causal contribution to the compound) in relation to the form (according to the notion of hypothetical necessity presented in $\mathrm{Ph}$. II 9). Roughly speaking, in $\mathrm{H} 4$ prevails a causal notion of matter that we do not find already developed in H2. But the two positions are compatible, since if matter is something definite (i.e. a substance) in that its dispositional properties are actualized by the form (i.e. the position of $\mathrm{H} 2$ ), what matter contributes to the explanation of the compound must be taken into account too (i.e. the position of $\mathrm{H} 4$ ). 
possible by means of the differences. Besides, the differences in the definitions correspond to the role of the forms in the material compounds (1043a7); as it is made explicit in 1043a5-7, there is an analogy between differences and forms. What is conveyed by Aristotle in "so in other definitions <the difference> is

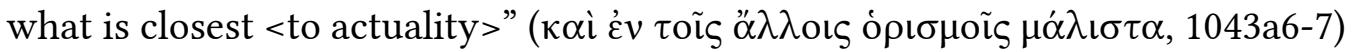
is just that in the realm of definitions the difference is what most closely corre-

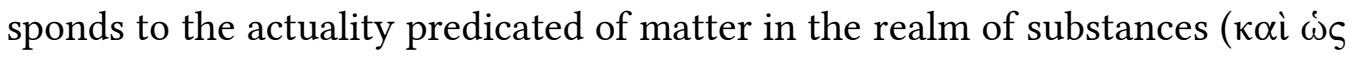

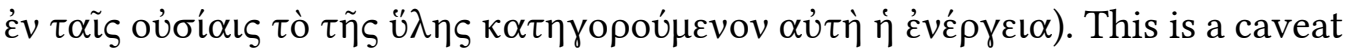
meant to clarify the previous claim that, strictly speaking, the differences are not substances (or forms) (1043a4): since the differences operate whenever we make definitions, as it was already established in 1042b25-26 and then illustrated in 1043b7ff, the differences must be analogous to substances. However, this is not to say that the differences are linguistic items. On the contrary, in

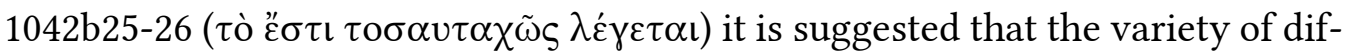
ferences helps to specify the many things that are and also the many ways in which these things are spoken of: what a threshold is or what a lintel is is different in virtue of the differences. ${ }^{56}$ Further, since the differences are explanatory of

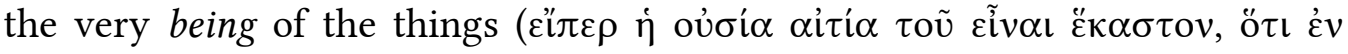

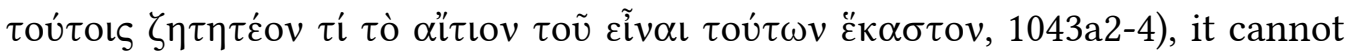
be wondered that the differences must be included in the definiens (of a real or

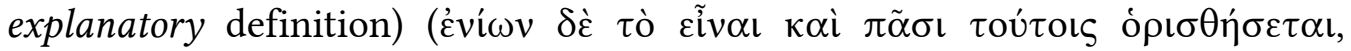
1042b28-29, see also 1043a7). We can get a better understanding of Aristotle's point if we take a look at his examples. Threshold is defined as wood or stone lying in such a position (1043a7-8). Lying in such a position -the definiens- corresponds to the difference, because this formula mentions the actuality that differentiates the disposition of what turns out to be the proximate matter of threshold (see also 1043a19-20).

Interpreters especially interested in discussing Aristotle's theory of definition of sensible substances focus particularly on the last section of $\mathrm{H} 2$ (1043a14-26). There, Aristotle contrasts the account or the definition of a compound by means of the potential matter with that by means of the actual form and the differences. If only matter is considered in the definiens, then we do not provide a proper definition, since matter is merely potential ( $\tau i \mathfrak{\varepsilon} \sigma \tau \iota v$ oikí $\alpha$, ö $\tau \iota$

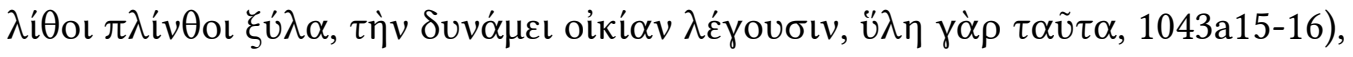
and so it is not enough to single out the essence of the thing. The definition must be always according to the form (1043a15-18). However, since we have to define a material compound, the proper definition must include the matter, i.e. it must take form and matter together (1043a18-21). Aristotle's model for these combined definitions is the same as that he already used for giving an account

56 "The 'is' of the threshold and the 'is' of the lintel are different [...] since being for the lintel means to lie in this particular way, while being for the threshold means to lie in a different way." Rapp 2018, 10. 
of threshold; ${ }^{57}$ and, in the end, this model seems to be also required for giving an account of the material substances as it was required in the first premise of the explanatory syllogism in Z17. ${ }^{58}$

This is certainly not the place to address at length this controversial topic. Yet I would like to make a remark in support of my suggestion that the combined definition is the only one that can have a full grip on the composition that

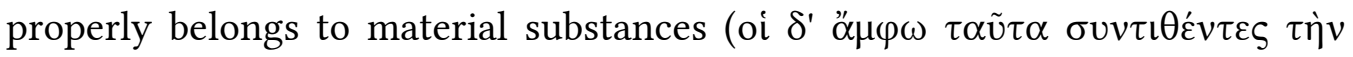

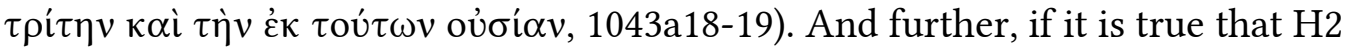
favors a combined account of material substances, how does this sort of definition relate to Z12's account by means of genus and differentiae? One plausible answer to this last question is given by Burnyeat; he suggests that Z12's model for definition corresponds to H2's definition by means of the form only -one should find something like the genus and the differentiae in 1043a1618. ${ }^{59}$ But it would be problematic to make both models of definition simply coexist, as if both were equally capable of grasping material compounds. Taking for granted that the definiendum in $\mathrm{H} 2$ are material substances, and further that it is not desirable to reduce their definiens to mention just the form -or the formal parts, like genus and differentiae as in "receptacle to shelter things and bodies"-, then we should take $\mathrm{H} 2$ as ranking the three definitions rather than putting them on the same footing. In fact, contrarily to Burnyeat's claim, Aristotle does not seem to accept in 1043a14-26 "with equanimity" that the three types of definition are acceptable. Rather, the coherent position that should be upheld by Aristotle would imply a ranking among these definitions, accepting as full definitions of compounds only those that put form and matter combined -i.e. the so-called definitions of this (form) predicated of this (matter), according to the examples in 1043a18-26.

\section{THE ARGUMENT AGAINST REDUCTIVE MATERIALISM IN H3}

H3 has been judged to present a rather entangled argumentation; furthermore, the scope of, at least, some of its claims seems to be controversial for interpreters (so are the reference to the Antisthenians in 1043b23-32 and the comparison between the unity of definition and the unity of number in 1043b32-1044a11). It also includes a possible later addition, which editors regularly print in brackets (1043b14-23). However, it is remarkable that the topics, the vocabulary, and the examples of H3 are those of $\mathrm{Z} 17$ and its sequel in H2. H3's likely contribution seems to consist in advocating the priority of form in 1043b5-14, which is

${ }^{57}$ He praises Archytas for having worked with combined definitions (1043a22-26).

58 This topic may be further elaborated by studying physical definition; see Metaph. Z10, 1035a4-6; Z11, 1037a30-33; E1, 1025a30ff; K7, 1064a19-28; Ph. II 2, 194a1-14; De An. III 4, 429b1314, b18-21; Cael. I 9, 278a22-b9.

${ }^{59}$ Burnyeat 2001, 74, 85f. 
followed by the discussion about the thesis of the Antisthenians in 1043b23-32, and it is then continued in 1043b32-1044a14, where H3 claims, once again, that form is irreducible to matter. These are the theses and the passages on which I will concentrate my attention in this and the following section. ${ }^{60}$

To begin with, let me take a quick look at the structure of the chapter; this is a particularly important issue since the common view on $\mathrm{H} 3$ as a set of several notes probably fueled the parallel view on the entire book as a miscellaneous work. ${ }^{61}$ I think, this rather negative assessment on the complex organization of $\mathrm{H} 3$ should be moderated. It is also interesting to take into account that, although most commentators share the view that H3-5 are a mere set of notes, some of them, at least recently, suggest that there is a project in H. However, even those accepting that $\mathrm{H}$ develops a project (which would be driven mainly by the introduction of the modal concepts of potentiality for matter, and actuality for form) dissent as to the very degree of conceptual and argumentative development of the book. In any case, an exaggerated emphasis placed on the miscellaneous feature of these chapters may lead to unjustifiably undermine our assessment on the real argumentative level of $\mathrm{H}$ as well as on its proper contribution to the development of the project initiated in Z17. ${ }^{62}$

The semantic issue, with which H3 begins (1043a29-b4), even if collateral to the main discussion of the book (1043a37-b1), is still rooted in H1, 1042a2431, where Aristotle picks up the question raised in Z3 about the three distinct ways in which a subject can be substance: matter, form, or compound can be subject, and therefore they fulfill a condition to be substance. The second section of H3 spans from 1043b4 to b23 (editors take 1043b14-23 as parenthetic); there, Aristotle discusses whether two of the three aforementioned ways of being a substance, i.e. the form and the compound, are subjected to generation

${ }^{60}$ The passage in 1043a29-b4 is closely connected with the last discussion of H2. There, Aristotle warns us about the ambiguity of sortal terms that can apply to the form and to the compound as well (in particular, whenever the compound lacks a proper denomination). Aristotle approaches this ambiguity by means of the focal meaning resource: the sortal term applies primarily to the form (since the form and its essence are one and the same, see 1043b2-

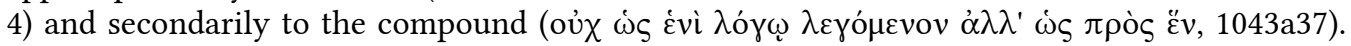
This topic is not immediately relevant to the present discussion on sensible substance (1043a38b1). Burnyeat 2001, 70 offers an interesting explanation about the semantic discussion of the beginning of $\mathrm{H} 3$ along the following lines: since $\mathrm{H} 2$ focuses on form as actuality, and it is evident that the form is the same as its essence, then it is evident that form is the first reference of the sortal terms. This interpretation relies on a passage of Z10 (1035a7-9).

${ }^{61}$ Such is the view of Ross 1924, II 231 and of Gill 1996, 210 on H3. Even a "linearist" on $\mathrm{H}$, like Burnyeat 2001, 69, 71, believes that $\mathrm{H} 3$ is a miscellany and that it is an appendix of memories and corollaries on form and matter.

${ }^{62}$ Authors currently working on the new image of $\mathrm{H}$ agree that this book carries out a project that mainly consists in a refined theory of material substance. For Burnyeat 2001, 71, H3 is a corollary to $\mathrm{H} 2$ and Z17 on the topic of substantial form; similarly, H4-5 is to him another corollary on matter, which connects with the last section of H1. Although, in that way, Burnyeat contributes to the overall recovery of H's unity and consistence, he continues holding that these chapters are, in the end, "a miscellaneous bunch of topics." 
and corruption. The position Aristotle holds there is in agreement with Z8's thesis about the incorruptibility of form. ${ }^{63}$ The third section of H3 (1043b231044a11) tackles a problem about definition and makes a comparison between substance and definition, on the one hand, and number, on the other; it also includes a section devoted to discuss a difficulty involved in a claim about definition held by the Antisthenians (1043b23-32). The chapter closes (1044b11-14) with a mention of the topics considered in the second and third sections.

H3's main argument for the priority of form in 1043b5-14 is based on the assumption that form is irreducible to matter -this is in line with Z17's irreducibility argument. Aristotle takes up there the practitioners of inquiry (1043b5) and he is somehow guided by them. It is important to note that, as I mentioned, this passage elaborates on the theses and the vocabulary of Z17 and H2; in par-

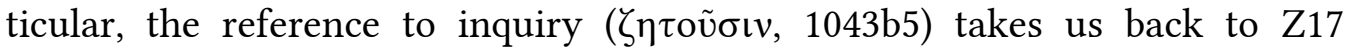

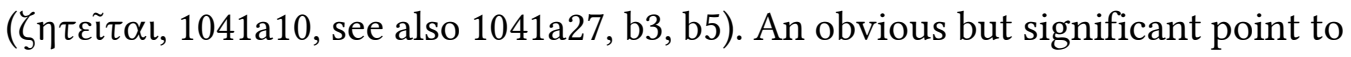
better understand the etiological approach of $\mathrm{H} 3$ is that, as in Z17, inquiry is mainly concerned with causal explanation. Aristotle makes the following remark: when we inquire, we do not put the form just besides the matter, i.e. we do not take a house to be bricks and stones plus some arrangement. I think, this is Aristotle's warning about a possible misunderstanding of the combined definitions he favored at the end of H2 (1043a18), since, in fact, we have to avoid that, in both causal explanations and definitions, form and matter are put together on a same footing. Otherwise, form would be another part of the compound -but this consequence was already rejected in Z17's irreducibility argument. Thus, compounds cannot be rightly described by merely including the

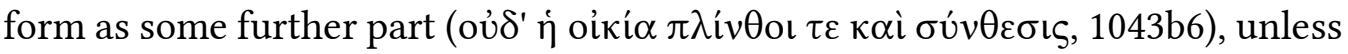
we are prepared to turn form into one further material part among the others (1043b7-8). The right approach to causal inquiry and to the definition of material substances require, on the contrary, to put the form as the main explanatory factor of the compound's being, i.e. to take the form as responsible for the specific arrangement of the material parts, which brings about a compound of some sort, e.g. the form of threshold that arranges wood or stone in a certain position (this resumes $\mathrm{H} 2,1042 \mathrm{~b} 19-20$ ) helps to explain what a threshold is, i.e. what the function of a beam at the bottom of a doorway is, but not the other way around -i.e. the beams do not really explain why are they in such a position at the bottom of a doorway nor what they constitute:

${ }^{63}$ This is possibly connected to the 8 th and 10 th aporiae from book B, where Aristotle raises the question as to whether the principles of corruptible things are corruptible or rather eternal. 
[...] if the threshold is by position, the position is not from the threshold, but rather this ${ }^{64}$ from that. ${ }^{65}$ (1043b9-10)

These lines admit two possible readings: a stronger and a weaker one. The weaker one claims that the position is not a further part of the compound. The stronger reading elaborates on a possible consequence of the weaker, to which it adds that what the compound and the matter are can be only explained by the form, i.e. the position is the cause of what some beams located at the bottom of an entrance are and what a threshold is. So, the position -the placeholder of the form in this example- helps to causally determine the beams as a constituent part and, on this basis, it classifies this object as a threshold. This is a variety of the syllogism of Z17, but in H2-3 Aristotle is more specific. A beam in such a position can only function as it is required by a threshold, in that the beam is an actual and constituent part of that working compound. According to the stronger interpretation, the position, as such, holds explanatory (and definitional) priority with respect to matter -even to the actualized matter- of the

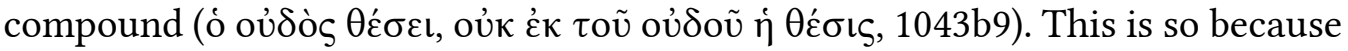
the actualized matter, i.e. that piece of wood of a certain length and with a certain resistance capability to hold the door's jambs together, is properly explained only by defining what is the function of a threshold, i.e. by the form or essence. Aristotle develops this argument by means of a criticism against reductive materialism, i.e. the position of those who turn over priorities that are considered as already established in the practice of inquiry. In fact, to explain what some composite thing is, reductive materialists wrongly resort to matter. Here, Aristotle attacks their position along the lines of his anti-reductionist argument of Z17:66

Nor is man, then, animal and two-footed ${ }^{67}$ But there must be something besides these, if they are matter; but $<$ this $>^{68}$ is neither an

${ }^{64}$ The threshold, i.e. the compound thing.

65 The position. The position is here the placeholder of form; so form cannot be explained or defined by means of the compound or by means of its materials (beams or stone).

66 This position amounts to provide a definition according to the potential matter -i.e. the first way of defining that is degraded by Aristotle when casting definitions in H2, 1043a1516.

${ }^{67}$ The problem raised here by Aristotle may include his own discussion in Z12 (i.e. why is a thing defined a unity?, 1037b11-12); but only as far as genus and differentiae are interpreted along the lines of Platonic Forms -which Aristotle already tried to avoid in Z12 (1038a5-8, b25-

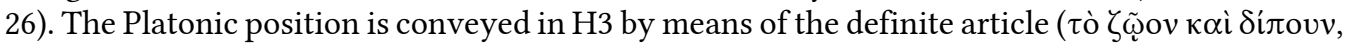

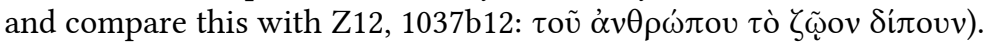

${ }^{68}$ What is to be a man. 
element nor made of an element ${ }^{69}$ but the substance ${ }^{70}$ which people who state the matter <are committed to> eliminate. If this is, then, the cause of $<$ man's $>$ being, and this is substance,${ }^{71}$ they will be failing to state ${ }^{72}$ the substance itself. $(1043 b 10-14)^{73}$

Interestingly enough, it turns out that reductive materialists -the people attacked here- are committed to hold the same position Aristotle rejected already in Z3 (1029a27), since they must endorse the opinion that only matter is substance (1043b13-14).

\section{A NOTE ON ESSENCE AND THE UNITY OF DEFINITION IN H3}

In the next section, Aristotle spells out this criticism more in detail. He takes up a reasonable difficulty one can raise by considering the position on definition and its correlate endorsed by the Antisthenians (1043b24ff). Aristotle (critically) remarks that, under a certain conception of essence and definition, the Antisthenians are committed to turn the essence into something impossible to be

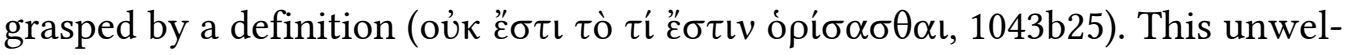
come result is, however, compulsory given their assumption about the "simples" and the sort of statement a definition is. Setting aside the controversial aspects of Aristotle's report and other details in his argument, ${ }^{74}$ I will confine myself to making a suggestion about specifying the systematic connection between this controversy with the Antisthenians and the rest of the chapter.

To my knowledge, what Aristotle tries to do here is to mark off a wrong notion of the sort of statement (logos) that a definition is. We begin with the general assumption that any definition is an account of the essence. ${ }^{75} \mathrm{~A}$ further assumption also anchored in Z4's core notion of essence is that essence must

${ }^{69} \mathrm{Z} 17$ claims that the arrangement (of the elements) is neither a further element (1041b20-22) nor something made of elements (1042b22-25).

${ }^{70}$ Keeping, with Ross, the reading of the mss. in 1043b12: $\dot{\eta}$ ov่ ${ }^{\prime} \alpha$ (against Christ's deletion, who is followed by Jaeger).

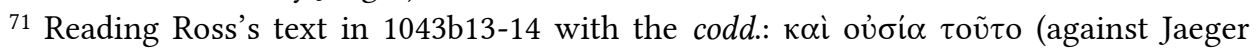
punctuation, who follows Bonitz's suggestion: oủ $\sigma i \alpha \varsigma, \tau o \tilde{\tau} \tau o)$.

${ }^{72}$ Reading oủ $\lambda$ ćyoıєv in 1043 b14 with the mss. EJ and Ross (followed by Detel) (against the omission of the negative particle in $\mathrm{A}^{\mathrm{b}}, \mathrm{Al}$ and Jaeger).

73 This translation is borrowed from Ross's and Bostock's.

${ }^{74}$ In Metaph. $\triangle 29,1024 \mathrm{b33}$, Aristotle grants to Antisthenes a commitment to "proper statement" or "one (name) for one (thing)," to which corresponds a conception of definition in terms of a sort of collection or combination of names. This may be the reason why Aristotle

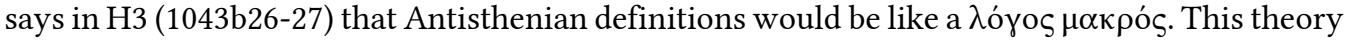
is probably echoed in Socrates's Dream in the Theaetetus (201e-202c). For a discussion see Brancacci 1990, chapter 8.

75 This general notion can be traced back to Z4, 1030a6-7. 
be something simple. ${ }^{76}$ It is relevant here to add the following question about substance and simplicity raised by the end of Z13 (1039a14-23). After having considered the composition of substances in the previous lines of that chapter -which are said to be made up neither of universals nor of further substances existing in actuality-, Aristotle suggests that we may be led to believe that any substance must be absolutely simple. But, as Aristotle remarks there, definable objects must have some sort of composition -at least, the one involved in the procedure of defining through division by means of genus and differentiae. It is quite obvious that these assumptions about ( $i$ ) the simplicity of substance and (ii) the composition of the object of definition overtly contradict the thesis of Z4 about the correspondence of definition and substance, since (iii) by being incomposites, substances will no longer be definable. ${ }^{77}$ In Z13 (1039a21-23), Aristotle leaves unsettled his discussion about the simplicity of substance and the compositionality constraint of definitions. But there are reasons to believe that by reconsidering $\mathrm{Z}$ and $\mathrm{H}$ we can find his way out of this dead end road. A thought that can help is the claim in Z4 that essences do not have the structure of "this in that," and, therefore, defining an essence does not involve a predicative struc-

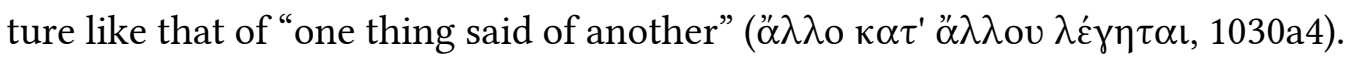
Thus, even if substance (or essence) must have some sort of composition to be the object of definition, it can be still, in a way, simple -at least, in that any essence is not like a compound.

This is the background against which, I suggest, Aristotle's note about the Antisthenians in H3 should be interpreted. In fact, he points out there the following difficulty (1043b24-25): if, according to the Antisthenians, we take

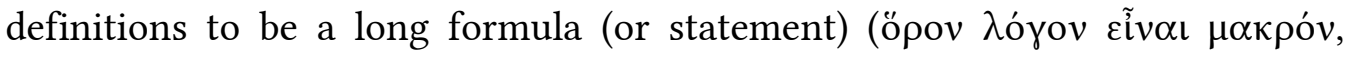

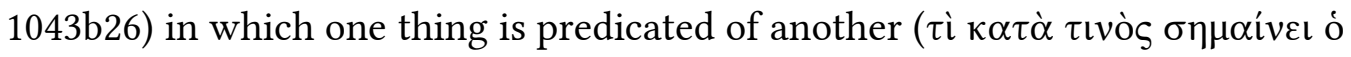

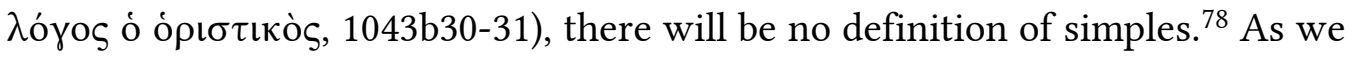
have seen, in Z12 and Z13 Aristotle seems to endorse that definitions are, in a way, complex formulae. In this context, the difficulty pointed out in H3 is that under an Antisthenian-inspired conception of the definitional formula as a sort of predication, there will be no grasping of simples -among which Aristotelians essences are located- in definitions. Similarly to Z13, Aristotle's strategy in H3 seems to be that of leaving this question open for the likely solution offered later on in H6.

${ }^{76}$ Aristotle puts essence in strong contrast to compounds that have the structure of this in that (Z4, 1030a4, a11). This is, of course, a constant assumption in the later discussions on definition in Z (e.g. Z12, 1037b24-27).

77 Bostock 1994, 226f warns that (iii) is in contradiction with Aristotle's official position in Z; for support, Bostock refers to Z4 (1030a7-14), Z10 and Z11 (1037a33-b7).

78 For describing simples, the Antisthenians would only accept comparisons (such as "silver is like tin"); but since they hold that any definition implies a complex structure, it would be impossible for them to provide an account of what it is for simples (1043b25-28). 


\section{H4: THE CAUSAL SPECIFICATION OF MATTER AS PROXIMATE}

H4-5 are the second duet that help to connect the chain of book $\mathrm{H}$ and to bridge the transition to the final thesis about the unity of compounds -including material substances- expressed in H6. In these two chapters, Aristotle resumes his previous consideration on matter as a potential subject involved in change launched by the end of H1 (1042a26ff and H2, 1042b9-10). The main theoretical contribution made by H4-5 consists in giving a justification of both the status of matter as a potential being and of matter's causal role in the constitution of a material compound. For that purpose, Aristotle first explains, in H4, that matter is cause in that it is proximate, and then, in $\mathrm{H} 5$, he goes on to clarify that matter is the subject of change -mainly, of substantial change- in that it is potential. It is only on the basis of these argumentative developments that it can be then easily accepted in H6 that (proximate) matter is (potentially) the same as the form of the compound..$^{79}$

The first link of this duet is H4; there, Aristotle takes care of explaining that the proximate matter is specified enough to have the required dispositional properties to really constitute the compound. Only when reaching that high specification level, matter can be material substance. Commentators usually distinguish two sections in H4. The first one, in 1044a15-32, presents the hierarchical specification of matters, and the second one, in 1044a32-b20, underlines the causal role of matter. By considering a special case in which there is no properly a material subject of change, Aristotle explains how to give an account about the material aspect of things that change without having a proper material subject. This consideration is linked to the previous passage by the topic already mentioned in 1044b5, which deals with the complete explanation we must always seek in inquiry. Let me start off with the first section, which, in view of the reconstruction of H's program, is certainly the most important one.

It is true to claim that, in a sense, in virtue of the hierarchical linkage of matters that compose a thing, very different material compounds share one and the same matter. This reasoning may be extended to all existing compounds in the world, and so we could eventually say that all things proceed from one and the same common matter, let us suppose, the four elements. ${ }^{80}$ On the basis of such reasoning, Aristotle opens his discourse to address matter in H4 (1044a1517); yet, his true purpose becomes clear only when he contrasts that purported common matter of all bodies with the proper matter of each thing. Shortly after, this proper matter will be said to be the only one that can really explain the material behavior of the thing it constitutes (1044a17-19) -in other words, only

${ }^{79}$ With this description of H4-5's role within H, I grant these chapters a programmatic role. Contrarily, Bostock 1994, 272 labels these chapters as "miscellaneous observations on matter.” Detel 2009, 603-29 assigns them the task of preparing H6.

80 This is suggested by Alexander 1891, 556, 6-8. 
the proper matter of each thing, which is its proximate (or first) matter, can play a causal role. The etiological approach to substance, which governs Aristotle's mind from Z17 on, can help us to understand his present claim: that only the matter that is proximate is cause, and therefore only proximate matter can be called material substance.

This may be so in order to disambiguate the expression "first matter"

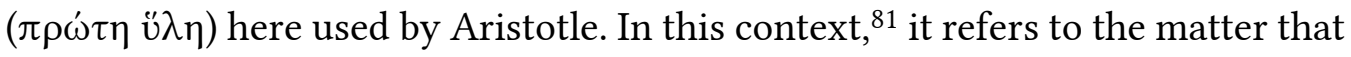
belongs immediately to the compound, e.g. the bronze of the statue, which is the matter that explains the main dispositional properties in the material performance of the statue (e.g. its hardness, temperature, heaviness etc.). The very fact that in each complex thing (like a statue or a living body) there is a (hierarchically ordered) linkage of stuffs contained, as Aristotle suggests in 1044a2022 , makes it necessary that whoever tries to causally explain the thing's performance, she places particular emphasis on singling out the explanatorily relevant matter of the thing. Let me now quote the crucial lines I mentioned above:

And there come to be several matters of the same thing when one is the matter of the next [...]. (1044a20-21)

Being that so, it turns out that it is an urgent task for inquirers to distinguish the preexisting from the constituent proximate matter of a compound. Aristotle's idea, as I understand it, is that some matter, let us call it $m_{i}$, could be explanatorily irrelevant with regard to some compound, even though $m_{i}$ is located in the very production line from which that compound comes to be. Nonetheless, $m_{i}$ is, in fact, irrelevant for the explanation of the compound's material performance just because that stuff is at a distant location from the thing's composition. So even though $m_{i}$ is causally linked to the compound, its location in the production line far from the proper features of the composition makes that stuff explanatorily tangential for the compound's performance. This reasoning leads to the assumption that the actual performance of a thing can be adequately explained only by means of its dispositional properties. In short, any remote matter, like $m_{i}$, which is in a loose connection with the dispositional properties realized in a complex (higher) thing, is powerless for the explanation of a compound located at a level of complexity that is considerably higher than that of $m_{i} .82$

To better understand the linkage of matters and the corresponding specification of matter at each level in the composition of material substances, it

${ }^{81}$ For similar contexts see $P h$. II 1, 193a29, 193a9-12; GA I 20, 729a32; Metaph. $\Delta 4$, 1014b32; $\Delta 6,1016 \mathrm{a} 19-20$ (all references are taken from Bostock 1994, 272).

${ }^{82}$ For many valuable remarks on this issue, see Kosman 1987. About Metaph. H4-5, see Morel 2015, 159-184 and Pfeiffer 2016, $19 \mathrm{ff}$ (who closely follows Code). 
may be useful to consider two different senses distinguished by Aristotle for

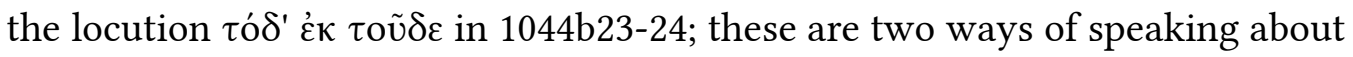
the provenance or the origin of something:

(1) A comes directly from $\{m, n\}$ in that $\{m, n\}$ is the matter of which $A$ is made;

(2) $A$ comes indirectly from $B$ in that $A$ comes directly from $\{m, n\}$, which are the matter of which $A$ is made, and $B$ is split up into $\{m$, $n\}$.

By means of this distinction, Aristotle gives an account of the possible double origin of some compounds; for instance, phlegm has a double origin that is explainable in terms of the aforementioned schema:

$\left(1^{*}\right)$ phlegm comes directly from fat, and fat comes directly from sweet;

$\left(2^{*}\right)$ phlegm comes indirectly from bile, and bile is split up into ${ }^{83}$ some stuff common to both bile and phlegm.

While in schema (1) there is a chained differentiation of materials that are hierarchically specified until getting to the proper and proximate matter of the compound (phlegm, whose matter is fat), in schema (2) it is considered only an indirect origin in that one compound comes from the other only as far as the compound of origin (i.e. $B$, representing bile) is split up into some stuff that (at a certain point) can give rise to the proper stuff of $B$ and $A$. Yet, this second model implies that the stuff into which the compound of origin is split up cannot be directly the proper matter of the compound that is the point of arrival (i.e. $A$, representing phlegm). Furthermore, the hierarchical specification of materials in schema (1) means that phlegm cannot come directly from sweet but only by means of fat. Taking fat as made of sweet implies considering fat as a compound (which is located at a lower level than phlegm and which probably is a less complex thing than phlegm), whose proper matter is sweet. ${ }^{84}$

Thus, the chain of matters implies that, even within a direct origin -as in schema (1)-, there are closer and more remote locations of materials. Coming back to schema (2), the matter into which bile decomposes must be the matter from which (at some farther point) the stuff of phlegm and bile can originate

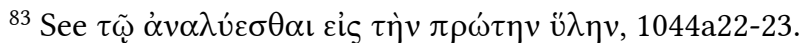

${ }^{84}$ Of course, the same consideration can be applied to sweet, taking for granted that sweet is not the stuff located at the most basic level (which is occupied by the four elements in the Aristotelian physical universe). The relation between more and less complex compounds is mirrored in the relation between organisms (wholes) and organs (parts). 
directly. According to this latter schema, the shared matter of $A$ and $B$ should be the origin of either sweet or fat or some other stuff within the same chain of direct composition. So, in a way, the indirect origin is reduced to the direct one, since $B$, as such, cannot be the matter of $A$ (bile is certainly not made of phlegm). By means of these two schemata, in sum, Aristotle provides an explanation of different ways of getting the origin of a compound, i.e. a direct and an indirect one. In a way, we can take them as having reverse directions, i.e. a forward and a backward movement, as suggested in 1044a24-25. According to the forward movement in schema (1), phlegm comes from materials that are in a forward direction (lastly) towards phlegm, i.e. onwards ( $\pi \rho$ ò ó $\delta$ oṽ). ${ }^{85}$ According to the backward movement in schema (2), bile is the origin of phlegm only as far as bile decomposes into (backwards) some stuff that is, lastly, common to both bile and phlegm. In sum, schema (1) concern material constitution, and schema (2) concerns origin. ${ }^{86}$ However, we can also get the constituent matter after schema (2), but only in a non-immediate way. ${ }^{87}$ From H4's etiological point of view, the most relevant distinction is that one between proximate and remote matter, whereas the distinction between two ways of getting the origin of something is subsidiary to the explanatory interest. ${ }^{88}$ As suggested above, this is a coherent and programmatic development of the same etiological point of view on substance launched in Z17. Lastly, H4's schema (1) and the clarification about proximate matter can be seen as a refinement of the idea conveyed in 1041b5: whenever we inquire about the cause of material substances, we end up by inquiring why some stuff constitutes a certain sort of thing.

Having considered this all, the former schemata may be deemed indeed to be a refinement in the theory because they help to better understand which matter in the chain of stuffs is really a cause: only the proximate matter can be constituent. Besides, the present theory also helps to clarify how Aristotle's model of a hierarchically ordered linkage of matters -the last specification of which the proximate matter is- really functions; and lastly, it helps to see why the hierarchical order of matters is relevant for the explanation of compounds.

Aristotle claims in 1044a20-21 that one and the same compound has sev-

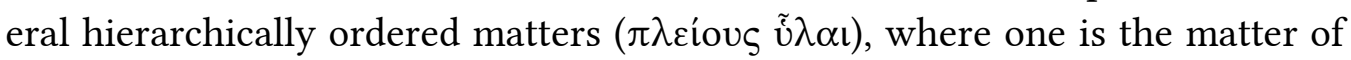
the next. This is of crucial importance for his explanatory model in $\mathrm{H}$. There are two significant consequences for the material explanation of a compound to be considered at this point. First, the very idea of a continuous hierarchy of matters, which are ordered according to being closer or farther in relation to

${ }^{85}$ See LSJ s.v.: further on the way, forwards.

${ }^{86}$ The statement of bile not being the matter of phlegm can help to better understand a claim made about eternal things in the second section of the chapter: the stars are made of some matter -let us say: ether- but, as eternal substances, they do not originate from any other thing.

${ }^{87}$ See Bostock 1994, $273 \mathrm{f}$ and Detel 2009, 604ff.

${ }^{88}$ The etiological interest of H4 is stressed by Detel 2009, 610ff. 
the highest compound, implies that the dispositional properties of the farther stuffs become specified step by step until the matter proper to the highest compound is fully constituted. As it was anticipated in a former section (see section 3 here above), Aristotle avoids any risk of having many actual layers of matters as being parts of one and the same compound. This is so because the various matters within a single compound must be distinguished between those farther and closer. This distinction implies, in turn, that the farther matters -which preexist to the highest compound-cannot be counted as the actual constituent matter of that compound. The only constituent matter, which is the proper material cause of the compound, is that closest matter whose dispositional properties are fully actualized in the compound. But, second, the chain of matters involved in a compound enables Aristotle to build a far-reaching explanation. And this makes possible for him to account for some performances of the bronze of a statue by means of the matter of which bronze is an alloy, i.e. copper and tin -the heaviness of a brazen statue is due to one of bronze's constituents, i.e. tin. So, even though tin is not the proximate and properly explanatory matter of a brazen statue, it can in fact explain some relevant aspects of the statue's performance just because tin is still effective in bronze -but, certainly, only as being part of bronze. Thus, tin's heaviness is integrated in the relevant dispositional properties of bronze, without the need of implying an actual layer of tin below the level of bronze. We might easily figure out a similar scenario for sweet, which is the matter of fat -which is, in turn, the constituent proper matter of phlegm in schema (1).

Another significant aspect of this model for material explanation is that even a farther located matter (or remote matter) in the production line of a compound can have a causal incidence on the compound's performance. On the contrary, a merely common shared matter located at some place at the bottom of many different compounds -as it is also easy to imagine with the help of schema (2) - (i.e. the remotest matter) would lack of any causal effectiveness as to the explanation of the higher compounds. Needless to say, such a scenario is akin to Pre-Socratic theories that commonly hold that a variety of things has a single material origin from which many things come directly. ${ }^{89}$ To avoid such a non-hierarchical model of matter, the meaning of the sentence at the outset of H4 (1044a16) should be conveniently restricted. Therefore, at the beginning of the chapter we should rather perceive a warning sign against Pre-Socratic style views on prime matter:

89 To claim, with Anaxagoras, that hair is like a seed, in which all constituents are contained, would be quite uninformative -to say the least- about the real behavior of hair, since a lot of different things -in fact, for Anaxagoras, all things in the universe- are supposed to be made of the same constituents. 
On material substance we must not forget that even if all things come from the same primary <matter $>$ or from the same < matter $>$ taken as primary, and even if it is the same matter that is like a principle for the things that come into being, nevertheless there is some proper $<$ matter $>$ for each thing [...] (1044a15-18)

As it is shown in schema (2), several distinct compounds can come from the same matter; this probably leads Aristotle to examine in 1044a25-32 the possible relations between a product and its matter when one or the other is replaced or remains constant. ${ }^{90} \mathrm{We}$ get the following four possible combinations:

(a) Multiple relation between different products and one and the same matter: the matter of $A$ can be also the matter of another (specifically different) thing, $B$. This is explained by the intervention of the efficient cause (a carpenter can make a chair or a chest from the same piece of wood).

(b) Single relation between product and matter: some things require some functionally suitable matter (a saw can be only made of some metals that are suitable for cutting). ${ }^{91}$

(c) Multiple relation between product and different matters: this is only possible when an efficient cause strictly governs the process (a bed can be made of wood or iron only under the intervention of the carpenter). ${ }^{92}$

(d) Multiple relation between product and matter: this is only possible if both efficient cause and matter are different. ${ }^{93}$

Since these combinations introduce many explanatory factors (matter, efficient cause, and form and goal involved in the functional consideration), they help us to understand better how the claim in 1044a33-34 -where Aristotle rounds off his explanatory model deeply rooted in the Analytics- must be taken. On the basis of texts like Posterior Analytics II 11, he argues there that any complete inquiry must give an exhaustive explanation by considering as many causes as possible. For the material explanation of $\mathrm{H} 4$, this implies that we must have into

${ }^{90}$ Bostock 1994, 273 rightly points out that this passage considers exceptions to that rule established in the first paragraph of the chapter; i.e. that for each thing there is only one proper matter.

${ }^{91} \mathrm{Ph}$. II 9, 200a10-13, 200a30-b8; PA I 1.

92 Variant of $(a)$.

${ }^{93}$ Variant of (c) that arises from deleting the constant factor in (c). 
account the proximate matter, since, as it has been shown, this is the only one that really explains the material performance of the compound (1044a33-b5). ${ }^{94}$

\section{H5: MATTER AS SUBJECT AND AS POTENTIAL BEING}

In $\mathrm{H} 5$, Aristotle examines problems concerning the material substrate of change. With this, he resumes the role granted to matter in H1 (1043a32-b8), but the discussion in $\mathrm{H} 5$ is enriched with H4's acquisitions. H5 continues discussing the issue raised in H4's second section; ${ }^{95}$ so, H5 starts with a distinction between things that have matter and change, on the one hand, and others that have neither of them, on the other hand. Two general ideas that are well known from the Physics are motorized here; first, that only things having matter can change -which takes place between opposites-; and, second, that matter is the subject of change. ${ }^{96}$ Later on, Aristotle examines two aporiae: the first one in 1044b29-32, and the second in 1044b32-1045a6, but the latter can be deemed to be a mere sequel of the former. If it is acceptable to say that $\mathrm{H} 4$ justifies that matter is substance because it plays a causal role as proper matter, then it is likely to assume that $\mathrm{H} 5$ purports to fulfill its own task of further justifying that matter is substance by showing that matter is the substrate of change. Thus, the project of each of these chapters is in strict correspondence with two main claims on matter already made in $\mathrm{H} 1$, i.e. that matter is something determinate

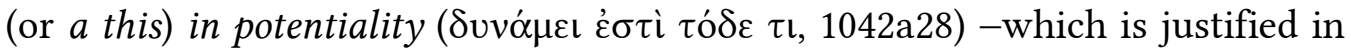
H4's thesis about the proximate proper matter- and further that matter is the

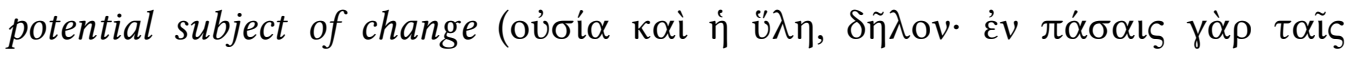

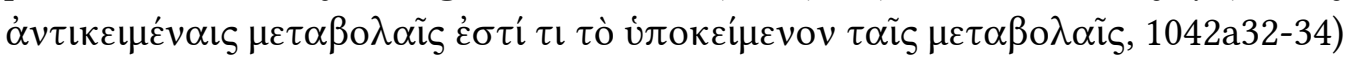
-which is justified in H5's clarification about how the same matter could be subject of generation and corruption. ${ }^{97}$

\footnotetext{
${ }^{94}$ In the second section of H4 (1044a32-b20), Aristotle considers two special cases for introducing matter as a cause. (a) Eternal substances do only have constituent matter, but, by being eternal, they cannot have an origin (1044b3-8). (b) Things by nature that are not substances (natural events, both in the external world and mental, as well as accidents) do not have matter or, rather, they have a substance as their own subject (moon for eclipse, heart for sleep) (1044b8-20). Perhaps, at least for sleep, there is, lastly, some material cause, since, for instance, some features of sleep, like the weakening of the capacity to perceive, is due to material factors in the heart (weakening of life activity due to digestion, which, in turn, has an effect on the cold blood running to the heart). (This process is described in De Somno 457a33458a10; PA I 7, 653a10-20.)

${ }^{95}$ Bostock 1994, 276 suggests that the connection is quite loose.

${ }^{96}$ Aristotle does not consider here substances changing only as regards place (i.e. having only local matter, H1, 1042b6; H4, 1044b7-8).

${ }_{97}$ As far as H5 considers reciprocal substantial change (processes of generation and corruption), it is not restricted to corruption, contrarily to what is claimed by Gill 1996, 223 and Detel 2009, 621.
} 


\section{ONE AND THE SAME MATTER IN DIFFERENT STATES: H5'S FIRST (AND SECOND) APORIA(E) ABOUT THE ROLE OF MATTER AS SUBJECT IN SUBSTANTIAL CHANGE}

The link of $\mathrm{H} 5$ to $\mathrm{H} 4$ is established by examining (in H5) the difficulty that has to do with some matters that can be subject of opposites in change ( $\pi \tilde{\omega} \varsigma \pi \rho$ ò

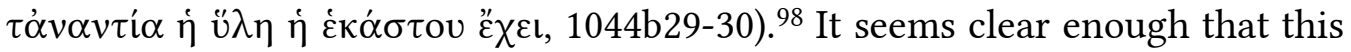
is a serious problem Aristotle's theory has to face, since if some stuff, let us say, water, is the matter from which wine comes to be directly (according to the schema (1) of H4), and granting that water has the right dispositional properties to be specified as wine, then it is hardly conceivable that the same stuff could be the matter of the opposite of wine, i.e. vinegar, for vinegar seems to require other dispositional properties in its proper matter. Of course, one way out to this problem is to sever all connections between opposites in substantial change -like that from wine to vinegar, or from living body to corpse. But, as we know, for several reasons mainly having to do with the condition of horizontal unity, this is not a thinkable way out for Aristotle. Let us now take a look at the presentation of the first difficulty:

There is a difficulty as to how the matter, which is of each thing, relates to the opposites. For instance, if the body is potentially healthy, and disease is opposite to health, is it potentially both? And, is the water potentially wine and vinegar? Or is it rather matter of one of them according to the dispositional property and the form, but matter of the other one according to the privation and the corruption that is contrary to <the opposite's > nature? (1044b2934). ${ }^{99}$

It is worth noticing that this passage relies on two previous claims. First, that matter is a constituent potential part of the compound (i.e. the matter of which something is made, according to schema (1) in H4). Second, the passage also relies on the general structure of change mentioned in 1044b23-24 (where the emphasis falls on the distinction between substrate as that which properly changes and opposites between which the change occurs). On this basis, Aris-

${ }^{98}$ The mention of substantial and accidental change in 1044b25-26 sets the stage for the next distinctions between the relation of matter to opposites and the relation the opposites hold with each other. Bostock 1994, 276 thinks that 1044b25-26 holds a position that would be contradictory with the official doctrine on change in $P h$. I 7, since he reads these lines as meaning that opposites originate one from the other without any intervention of the substrate.

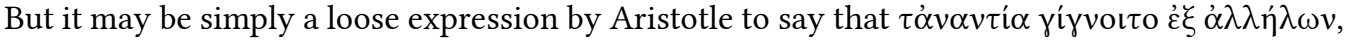
which does not contradict the thesis that any change operates on a substrate. See Ross 1924, II 236.

${ }^{99}$ Following Ross's translation and including modifications. 
totle raises here the following questions: $(a)$ can the same matter be, as the subject of change, potentially constituent of both opposites equally? Or rather $(b)$ can matter play that role only as much as it relates to each opposite in a different way? To be more precise on option $(b),(i)$ does matter relate to the (positive) form resulting from its change according to its dispositional property and its very

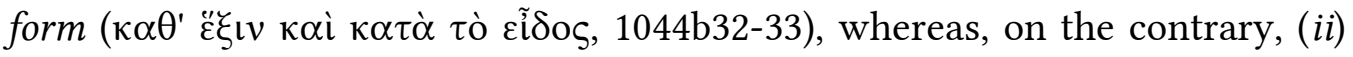
matter relates to the (negative) state resulting from change only according to the privation and the corruption (of the own former dispositional properties actual-

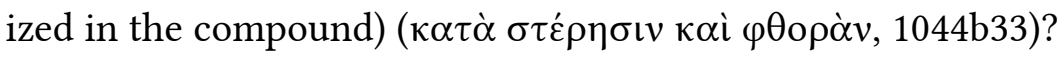

Interestingly enough, Aristotle does not fully develop or solve this difficulty in the present chapter. ${ }^{100}$ However, H4's theory about constituent proper matter provides us with adequate means to settle this question in favor of option $(b)$. This is so because Aristotle has already shown that, as far as the material substrate is a constituent part of the compound -and in order for it to be so, matter cannot be "undifferentiated," similarly to the indeterminate residual substrate reached after having eliminated all properties and dispositions from a given thing in the thought experiment of Z3-, it can be potentially the thing that matter generates only according to its (i.e. of the matter) dispositional properties. Yet, if there must be a continuity also in substantial change, and granting that this continuity can be guaranteed only by assuming one and the same matter for the opposites, then Aristotle must give an account of how could one and the same matter be the subject of change between the opposites. More precisely, he must explain how it is possible that one and the same matter is the subject of the negative state that results from the corruption of the previous positive state (as in the case of corpse that comes from the corruption of a living body).

Aristotle assumes that the matter required for grounding the necessary continuity of change is, on the one hand, one and the same matter. But, in order to explain the double role played by (one and the same) matter as the subject of opposites, he must add that, on the other hand, such a matter can be the subject of change only in that its dispositional properties -i.e. those dispositional properties that were realized in the positive state- have been already corrupted. Inasmuch as these properties were those defining the matter as constituent for the positive state -for example, grape juice for wine-, after matter has suffered the radical change that gives rise to vinegar, it must have already lost its proper features. That is why Aristotle can describe the condition of matter when it is the subject of the (negative) opposite as having properties that are contrary to its (previous) nature (as constituent for the positive state, i.e. wine) ( $\pi \alpha \rho \dot{\alpha}$

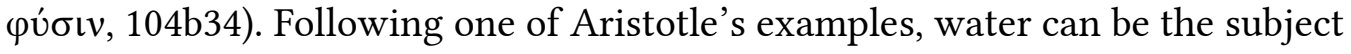

${ }^{100}$ For an analysis, see Code (unpublished). 
of vinegar only in that water's dispositional properties actualized as constituent part of wine have been already corrupted.

In order to better grasp the different conditions in which one and the same matter must be subject of opposites in substantial change, we can make the following distinctions. A subject can be the material cause of a product that is the result of the specification of the matters' dispositional properties -as it is water or grape juice for wine- only if that subject is in a certain condition, $m_{F}{ }^{101}$ in which it is in potentiality the same as the form of the product that results from the matter's actualization. This is the matter fully specified by the form $(F)$ (wine) as a constituent part of the compound ( $\tau$ ov $\mu \dot{\varepsilon} \nu \kappa \alpha \theta^{\prime}$ '̌ $\xi \iota \nu \kappa \alpha \grave{~}$ $\kappa \alpha \tau \grave{\alpha} \tau$ ò $\varepsilon i \tilde{\delta}$ os $u ̈ \lambda \eta, 1044 b 32-33)$. But after a radical change, the same matter can become $m_{C}{ }^{102}$ under another specification, i.e. under the specification provided by the opposite form $(G)$, which makes matter be in a different condition. In this latter condition, the matter $m_{C}$ is potentially the same as $G$ (vinegar), and so $m_{C}$ gives rise to a product that is the result of the corruption of its (i.e. matter's)

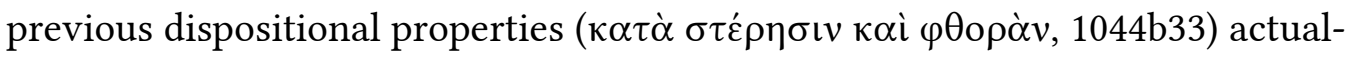
ized in the (positive) compound.

In 1045a3-5, we read that things that change into one another $(\mu \varepsilon \tau \alpha \beta \dot{\alpha} \lambda \lambda \varepsilon \varepsilon$ عiऽ ’ $\alpha \lambda \lambda \eta \lambda \alpha, 1045 \mathrm{a} 3-4)$, such as wine and vinegar or living body and corpse, cannot share exactly the same matter and use them immediately as their subject. The matter of corpse can be the matter of a living body only if the matter returns (is split up) into some lower matter that can develop (as a result of a specifying process) the dispositional properties that are necessary to generate the living body -i.e. those dispositional properties that cannot be immediately provided by the matter of a corpse being in the condition it is, since, in the above introduced terms, $m_{C}$ is specified contrarily to $m_{F}$. This is also implied in Aristo-

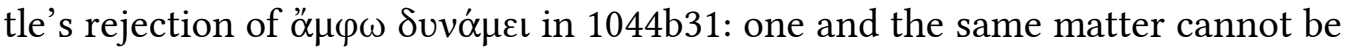
potentially both opposites immediately and in the same condition. Consequently, Aristotle there favors the alternative $(b)$ that consists in accepting two different specifications of (one and the same) matter, i.e. according to the form and according to privation (1044b32-34). ${ }^{103}$

H5's difficult lines 1044b34-36 introduce the second (and subsidiary) aporia (1044b34-1045a6), which further elaborates on the distinction between constituent and preexisting matter. It deals with the change of one thing into another (1045a3-4), already mentioned here above, and its main question is how one opposite relates to the other one in substantial change. The means for its solution are already at our disposal. One opposite cannot be made of the other's proximate matter. Thus, even though corpse and living body can come one from

101 To be read as "matter for form."

102 To be read as "matter of the corruption."

103 Bostock 1994, 277f provides a different interpretation. 
the other (remember schema (2) of H4), the constituent matter of each of them

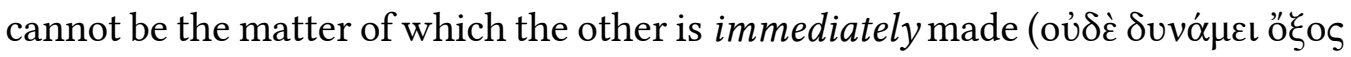

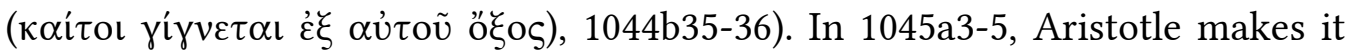
explicit that the decomposition of a compound in its matter results in its preexisting matter; and this is like a precondition under which it is possible to get a new suitable stuff -i.e. the same matter under a different condition- for the opposite:

And those things, then, that change into one another in this way must revert to their matters; for instance, if an animal comes from a corpse, $<$ the corpse must revert $>$ to its matter, first, and then it can become an animal < from this matter $>$ in this way; and similarly does vinegar that $<$ must revert, first, $>$ to water, and then, in this way, $<$ it can become $>$ wine. $(1045 \mathrm{a} 3-6)$

The decomposition ( $\dot{\pi} \pi \nu \varepsilon \lambda \theta \varepsilon \tilde{\imath} v$ : to go back, to return, to revert, to be reduced) in 1045a4 is now explained as a constraint to undergo the reciprocal change between opposites; ${ }^{104}$ and the process of reciprocal change between compounds must be understood in terms of the splitting up of a compound into its matter

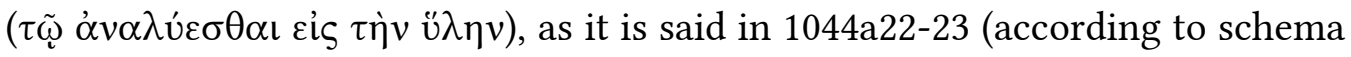
(2) in $\mathrm{H} 4)$.

The controversial lines in which Aristotle presents his second (and subsidiary) aporia of the chapter deserve a special consideration. Let me start quoting them in a translation:

There is also a certain difficulty over why it is that wine is not matter of vinegar, nor is it potentially vinegar (even though vinegar comes from it), and similarly the animal is not potentially a corpse. $\mathrm{Or}<$ this is $>$ not $<$ a difficulty $>$, but rather corruptions occur by accident, and the matter of the animal is also, according to <its> corruption, itself the matter that is the potency of a corpse, and water $<$ similarly $>$ in relation to vinegar. $(1044 \mathrm{~b} 34-1045 \mathrm{a} 2)^{105}$

104 Aristotle seems to limit the cases in which reciprocal change occurs between

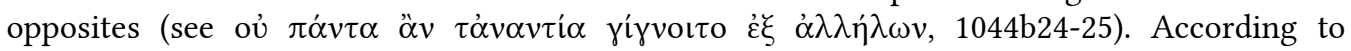
Alexander 1891, 560, 4-15, since nothing involves its own destruction, wine cannot be potentially vinegar; wine's destruction is rather the result of being deprived of its own form. See also Ross 1924, II 236f. Bostock 1994, 278 rejects Aristotle's apparent claim that the destructions occur by accident (but see the discussion on this point here below). Detel 2009, 626 also stresses that losing its own form is accidental for a thing.

${ }^{105}$ I here borrow both from Ross's and Bostock's translations (with some modifications). 
The general model above suggested for grasping Aristotle's examples is as follows: the matter of wine cannot be immediately the matter of vinegar -although it must be in a way vinegar's matter, as Aristotle claims here in 1045a1-2: $\dot{\eta} \delta \grave{\varepsilon}$

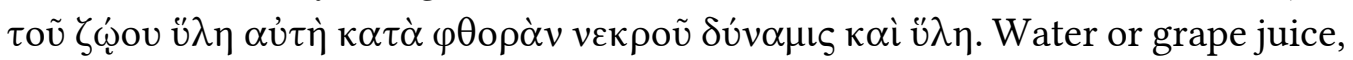
taken as the matter of wine, are its proximate stuff and constituent part; therefore, this high specification makes it unsuitable to perform opposite functions. This is less dramatic, but not different, only when the opposite is, like in the example of corpse, something deprived of any function. However, at the same time, since vinegar comes from wine (and wine from vinegar), they must share some lower preexisting matter that guarantees that the matter of one opposite can also be the matter of the other one. This is horizontal unity in substantial change. But the lower matter is certainly not the proximate one of either of them -otherwise, the vertical unity of compounds would be severely damaged by having assumed that each compound is made of an insufficiently specified matter.

So, under the here sketched model, we can analyze the text as follows. ( $i$ ) The constituent matter of wine (in the condition it is, i.e. as being highly specified as the potential matter of wine) cannot be the potential matter of vinegar. This means that, let us say, grape juice (i.e. the constituent material part of wine) is neither the constituent matter of its opposite (vinegar) nor, as such, vinegar in

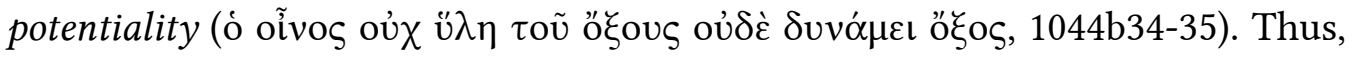
the constituent matter of wine as such is not the constituent matter of vinegar; nor can it be vinegar in potentiality. (ii) This may present a difficulty, as I have already said, because wine and vinegar originate from the other -as it is stressed by Aristotle in the formulation of the difficulty by means of the concessive

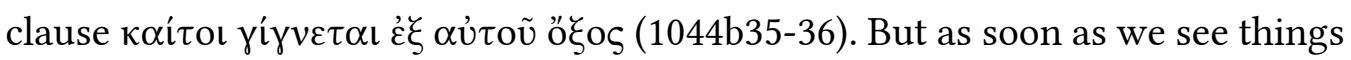
closer the difficulty disappears. This is what Aristotle goes on to suggest in $\ddot{\eta}$ oü, $\dot{\alpha} \lambda \lambda \dot{\alpha}$... (1044b36). So we get his own solution: (iii) we have to think of

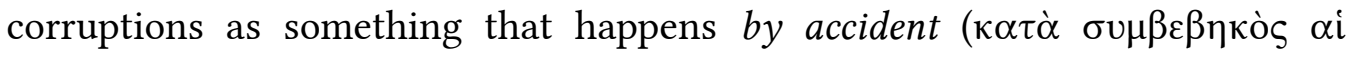

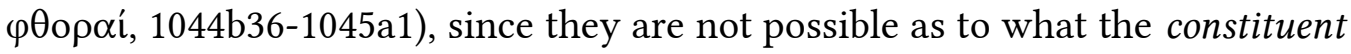
matter is by itself. This does not mean that corruptions are accidental changes, perhaps like alterations or quality changes. We already know from other treatises that Aristotle considers substantial change as much more radical than accidental change, since the former, unlike to the latter, involves a change in

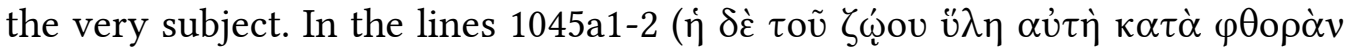

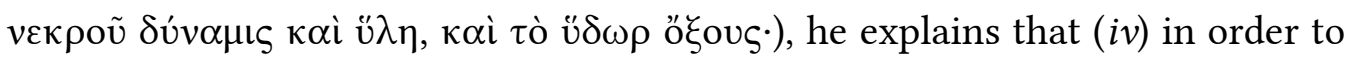
be the subject of substantial change (between wine and vinegar), some matter must change radically, i.e. the highly specified matter of wine must be deprived of its proper features as constituent of wine, and, only after having returned to a condition of lower specification, the same matter under a different specification can be in potentiality the subject of the opposite, i.e. vinegar. Finally, $(v)$ it is

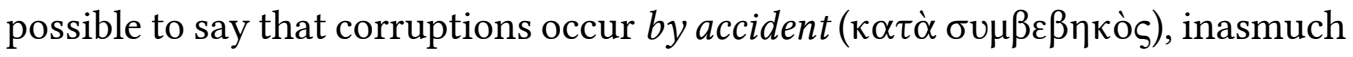


as the constituent matter of the compound of origin (wine) can be the matter of the opposite (vinegar) only by being deprived of all its proper features ( $\kappa \alpha \tau \grave{\alpha}$ $\varphi \theta$ o $\dot{\alpha} v)$. Thus, the matter of wine is not by itself the matter of vinegar, but rather only by accident, i.e. in that its dispositional properties as constituent part of wine are corrupted.

\section{FINAL REMARKS: A FLASHBACK TO THE "SHALE” OF H1-5}

Gill spots that in H4-5 Aristotle is still trapped in a problem. Accordingly, in vinegar, water (i.e. the matter of wine that has passed-away) remains as something determinate and actually existing; this gives rise, lastly, to Gill's diagnosis about the compound's lack of unity. ${ }^{106}$ When considering these things, however, it seems more plausible to think that $\mathrm{H} 4-5$ provide important evidence against this sort of interpretation, since precisely the discussion of the second aporia of $\mathrm{H} 5$ strongly suggests that we must rather not take water as persisting through change with all its constituent features. Water remains through the substantial change from wine into vinegar only in that its constituent features (as

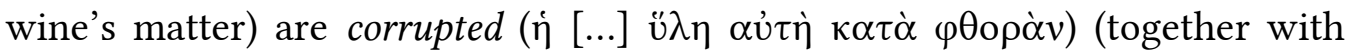
wine's passing away). This means that the water supplied with the specific features that made it the matter of wine (wine's constituent stuff) does not persist through change. So from this we cannot infer, as Gill does, that the actual water -which would build an independent layer within the compoundis (constituent) part of vinegar. In order to guarantee continuity Aristotle does not need to assume such a complete matter at a lower layer within the material compound (or within the opposites involved in change); it may be enough for him to allow certain dispositional properties (necessarily located at a lower level of specification) to remain crossing and connecting the opposites. Otherwise, he would only get an accidental unity for material substances: a unity between a matter that is complete and independent, on the one hand, and a form that must be superimposed, on the other. This, evidently, cannot square with H6's unity thesis (1045b17-19). ${ }^{107}$

To conclude, I may take a brief look back at H1-5's developmental path and now get a picture of the complex figures we have observed in their fabric of material substance. Contrarily to the common view on H1-5 that finds in

\footnotetext{
106 Gill 1996, 225ff.

107 To explain that thesis, Detel 2009, 623ff adds an important improvement to Gill's "construction model," for he suggests that there is a partial identity between matter and form. This helps to avoid both plain identity and a mere coincidental identity. See Detel 2009, 199f: "Wie nach den Analysen in VII 12 und VIII 2-5 bereits festeht, bilden allgemeine Form-MaterieKomposita eine Einheit, weil die Formen der Materie die Disposition aufweisen, von einer höheren Form geprägt und spezialisiert zu werden, und weil ferner diese Spezialisierung tatsächlich vorliegt und damit die Form des Kompositums und die Form der Materie essentiell zusammenhängen."
} 
these chapters little more than sparse notes on several topics of book $\mathrm{Z}$, I have tried to show that, after a careful observation, these chapters are the argumentative chain linking Z17's innovative thesis to H6's revolutionary solution. Both extremes are bound together in that Z17's thesis on form as cause is refined in H6's thesis about the identity of the actual form and the potential matter. The very point of departure of these inquiries in Z17's etiological approach is spread onto H1-5, where form and matter are constantly dyed by this coloring -they are examined as causes, and so the main problems raised in these chapters concern the explanatory priority of form (H2-3) as well as the identification of the matter that properly constitute and explains the compound's performance (H45). ${ }^{108}$ Instead of considering H1-5 as mere miscellaneous notes on Z, or instead of reducing the significance of the entire book to a few triumphant lines in H6 that solve all problems at one stroke, we must better go back to H1-5 for argumentative details that can be part of a larger program. A rich shale is then revealed, in which Aristotle works in his fabric of material substance by fueling Z17's etiological approach with a fine-grained argumentation whose contribution is far from being exhausted by the modal translation ${ }^{109}$ (i.e. potentiality for matter, and actuality for form) of the already firmly established hylomorphism of Z17. ${ }^{110}$

108 "In short, Z17 is a continuous presence in $\mathrm{H}$, which reads well as a development of the discussion freshly started there.” Burnyeat 2001, 73.

${ }^{109}$ Certainly, as we cannot repeat often enough (see, for instance, Morel 2015, 12, 23 (passim) and Burnyeat 2001, 74, 76).

110 This paper was written with the support of two generous foreign institutions: the Alexander von Humboldt-Stiftung (from which I received a generous fellowship between 2012 and 2015 to work out a project on Aristotle's hylomorphism in the Metaphysics) and the Deutscher Akademischer Austauschdienst during happy stays at the University of Munich (LMU). I warmly thank my host in Munich, Prof. Dr. Christof Rapp, for his support, comments and advice in seminars and talks. I also had the opportunity to discuss in Munich on Metaphysics $\mathrm{Z}$ and $\mathrm{H}$ with Dr. Christian Pfeiffer, whom I am very grateful. For the long and constant exchange of ideas on these topics, I owe a lot to my friend and host at the Universidad de los Andes (Santiago de Chile), Prof. Dr. Jorge Mittelmann. The Universidad de los Andes continues funding our multiannual cooperation. A Spanish shorter version of this paper was read as inaugural conference at the 5th Congress of the Latin-American Association of Ancient Philosophy (ALFA) at the Federal University of Rio de Janeiro in September 2017, and sections of previous drafts were also presented at the Universidad de los Andes during my stays there in 2016 and 2017. In March 2017 I was invited to lecture on Metaphysics $\mathrm{H}$ in the Doctoral Program of the Università degli Studi di Macerata (Italy). To all these friendly audiences and the sharp questions they raised I am deeply indebted. I also thank my colleague in Santa Fe, Manuel Berrón, for the long-standing work together on these and other Aristotelian topics. My work is supported in my country by CONICET and two projects funded by the Agencia Nacional de Promoción Científica y Tecnológica (PICT 2016-2128) and the Universidad Nacional del Litoral (CAI+D 2016-PI 5012015010062LI). Last, but not least, I warmly thank the Editor of this volume, Prof. Dr. Gabriela Rossi, for her patience and comments, and to the anonymous referees for useful suggestions. For her help with the English I also thank María Inés Fidalgo (CONICET-Universidad Nacional del Litoral). Of course, all remaining mistakes are my own. 


\section{REFERENCES}

Ackrill, John L. 1972/73. "Aristotle's Definition of Psuche," Proceedings of the Aristotelian Society 73: 119-133.

Alexander Aphrodisiensis. 1891. In Aristotelis Metaphysica Commentaria, edited by M. Hayduck Berlin: Reimer.

Angioni, Lucas. 2008. As Noçoes Aristotélicas de Substância e Essência. O Livro VII da Metafísica de Aristóteles. Campinas: Unicamp.

Baghdassarian, Fabienne. 2014. "Aristote, Métaphysique H 5: La génération des contraires et la matière," Elenchos 35/1: 61-88.

Balme, D. M. 1992. Aristotle De Partibus Animalium I and De Generatione Animalium I (with passages from II. 1-3). Translated with Notes. With a Report on Recent Work and an Additional Bibliography by Allan Gotthelf. Oxford: Oxford University Press.

Barnes, Jonathan. 1995. The Complete Works of Aristotle. The Revised Oxford Translation. Edited by J. B. 2 volumes. (Bollingen Series LXXI). Princeton: Princeton University Press.

Bostock, David. 1994. Aristotle's Metaphysics. Books $Z$ and H. Translated with a Commentary. Oxford: Oxford University Press.

Brancacci, Aldo. 1990. Oikeios logos. La filosofia del linguaggio di Antistene. Napoli: Bibliopolis.

Burnyeat, Myles. 2001. A Map of Metaphysics Z. Pittsburgh: Mathesis.

Burnyeat, Myles et alii (quoted as Londinensis). 1984. Notes on Books Eta and Theta of Aristotle's Metaphysics. Oxford: Sub-Faculty of Philosophy.

Charles, David. 1994. "Matter and Form: Unity, Persistence, and Identity." In Unity, Identity, and Explanation in Aristotle's Metaphysics, edited by T. Scaltsas, D. Charles \& M.L. Gill, 75-105. Oxford: Oxford University Press.

Code, Alan. 1984. "The Aporematic Approach to Primary Being in Metaphysics Z." In New Essays on Aristotle, edited by Francis J. Pelletier and John KingFarlow, 1-20. Guelph (Ontario): University of Calgary Press.

Code, Alan. (unpublished) "Aristotle on the Matter of Corpses in Metaphysics H5."

Delcomminette, Silvain. 2014. "Métaphysique H 6: Unité de l'ousia, unité de l'eidos," Elenchos 35/1: 89-125.

Detel, Wolfgang. 2009. Aristoteles, Metaphysik Bücher VII und VIII. Aus dem Griechischen von W. Detel und J. Wildberger. Kommentar von W. Detel. Frankfurt am Main: Suhrkamp.

Devereux, Daniel. 2003. "The Relationship between Books Zeta and Eta of Aristotle's Metaphysics," Oxford Studies in Ancient Philosophy 25: 159-211.

Frede, Michael and Patzig, Günther. 1988. Aristoteles, Metaphysik Z. Text, Übersetzung und Kommentar. 2 volumes. München: Beck.

Frede, Michael. 1994. “Aristotle's Notion of Potentiality in Metaphysics $\Theta$. ." In Unity, Identity, and Explanation in Aristotle's Metaphysics, edited by T. Scaltsas, D. Charles \& M.L. Gill, 173-193. Oxford: Oxford University Press. 
Galluzzo, Gabriele. 2006. "Metaphysics Z: Contemporary Interpretations." In Aristotle's Metaphysics Book Z: The Contemporary Debate, edited by Gabriele Galluzzo and Mauro Mariani, 61-211. Pisa: Edizione della Normale.

Gill, Mary Louise. 1989. Aristotle on Substance. The Paradox of Unity. Princeton: Princeton University Press.

Gill, Mary Louise. 1996. "Metaphysics H 1-5 on Perceptible Substances." In Aristoteles, Metaphysik. Die Substanzbücher $(Z, H, \Theta)$, edited by C. Rapp, 209-228. Berlin: Akademie.

Gill, Mary Louise. 2006. "First Philosophy in Aristotle." In A Companion to Ancient Philosophy, edited by M. L. Gill and Pierre Pellegrin, 347-373. Oxford: Oxford University Press.

Gill, Mary Louise. 2010. "Unity of Definition in Metaphysics H.6 and Z.12." In Being, Nature, and Life in Aristotle, edited by James G. Lennox and Robert Bolton, 97-121. Cambridge: Cambridge University Press.

Gould, Stephen Jay. 1989. Wonderful Life. The Burgess Shale and the Nature of History. New York: Norton.

Harte, Verity. 1996. "Aristotle's Metaphysics H 6 - a Dialectic with Platonism," Phronesis 41: 276-304.

Hussey, Edward. 1983. Aristotle, Physics. Books III and IV. Translated with Introduction and Notes. Oxford: Oxford University Press.

Jaeger, W. 1957. Aristotelis Metaphysica. Recognovit brevique adnotatione critica instruxit W. J. Oxford: Oxford University Press.

Kosman, L. A. 1969. “Aristotle's Definition of Motion," Phronesis 14: 40-62.

Kosman, L. A. 1987. "Animals and Other Beings in Aristotle." In Philosophical Issues in Aristotle's Biology, edited by Allan Gotthelf and James Lennox, 360-391. Cambridge: Cambridge University Press.

Lewis, Frank. 1996. "Aristotle on the Unity of Substance." In Form, Matter, and Mixture in Aristotle, edited by Frank Lewis and Robert Bolton, 39-81. Los Angeles: University of Southern California.

Lewis, Frank. 2013. How Aristotle gets by in Metaphysics Zeta. Oxford: Oxford University Press.

Liddell, H. G. and Scott, R. 1992. A Greek-English Lexicon. Compiled by L. and S. Revised and augmented throughout by Sir H. Stuart Jones with the assistance of R. McKenzie and with the co-operation of many scholars. With a Supplement (1968) edited by E. A. Barber with the assistance of P. Maas, M. Scheller and M. L. West. Oxford: Oxford University Press.

Loux, Michael. 1991. Primary Ousia. An Essay on Aristotle's Metaphysics $Z$ and $H$. Ithaca and London: Cornell University Press

Loux, Michael. 1995. "Composition and Unity: An Examination of Metaphysics H 6." In The Crossroads of Norm and Nature, edited by May Sim, 247-279. Lanham (Maryland): Rowman \& Littlefield.

Makin, Stephen. 2006. Aristotle, Metaphysics Book $\Theta$. Translated with an Introduction and Commentary. Oxford: Oxford University Press. 
Menn, Stephen. The Aim and the Argument of Aristotle's Metaphysics (unpublished, available at: https://www.philosophie.huberlin.de/de/lehrbereiche/antike/mitarbeiter/menn/contents )

Morel, Pierre-Marie. 2015. Aristote, Métaphysique Livre Ėta. Introduction, traduction et commentaire. Parin: Vrin.

Pfeiffer, Christian. 2016. "Metaphysik H.” (unpublished).

Rapp, Christof. 2018. "Diaphorai in Aristotle, Metaphysics H 2.” (unpublished).

Rhenius, Ralph. 2005. Die Einheit der Substanzen bei Aristoteles, Berlin: Akademie.

Ross, W. D. 1924. Aristotle. Metaphysics. A Revised Text with Introduction and Commentary. Oxford: Oxford University Press.

Ross, W. D. 1936. Aristotle, Physics. A Revised Text with Introduction and Commentary. Oxford: Oxford University Press.

Ross. W. D. 1949. Aristotle, Prior and Posterior Analytics. A Revised Text with Introduction and Commentary. Oxford: Oxford University Press.

Seminara, Simone. 2014. Matter and Explanation. On Aristotle's Metaphysics Book H. Universitè de Lyon - Roma Tre University (Doctoral dissertation; unpublished).

Seminara, Simone. 2018. "Are there Two Accounts of Hylomorphism in Metaphysics Book H?” Méthexis 30: 98-112.

Steinfath, Holmer. 1996. "Die Einheit der Definition und die Einheit der Substanz. Zum Verhältnis von Met. Z 12 und H 6." In Aristoteles, Metaphysik. Die Substanzbücher $(Z, H, \Theta)$, edited by C. Rapp, 229-251. Berlin: Akademie.

Vigo, Alejandro 1995. Aristóteles, Física. Libros III-IV. Traducción, introducción y comentario. Buenos Aires: Biblos.

Wedin, Michael. 2000. Aristotle's Theory of Substance. The Categories and Metaphysics Z. Oxford: Oxford University Press.

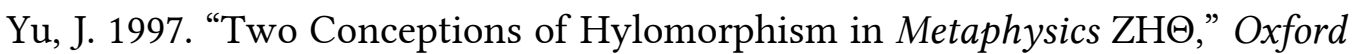
Studies in Ancient Philosophy, 15: 119-145. 